\title{
El papel de las automanifestaciones en las terapias cognitivo-conductuales
}

\section{Francisco Bas Ramallo}

Centro de Terapia y Modificación de Conducta (Madrid)

\section{INTRODUCCION}

Hay diferentes modos para expresar lo que nos decimos a nosotros mismos: «diálogo interno», «pensamientos automáticos», «automanifestaciones», «sentencias internas», etc. El tema de las automanifestaciones (AM) ha adquirido a lo largo de los últimos años un interés especial por sus implicaciones en el campo de la evaluación y la intervención en psicopatología. La introducción de las corrientes cognitivistas en el ámbito de la práctica conductual ha favorecido un análisis funcional más detallado y preciso del rol que pueden jugar las $\mathrm{AM}$ en la génesis, el mantenimiento y evolución de ciertas disfunciones. El interés es tan notorio que en la actualidad empieza a hablarse del posible desarrollo de una taxonomía semántica vinculada a cada una de estas áreas clínicas.

Pero ¿qué hay tras la AM? Algunos suponen que una estructura cognitiva soporte que, siguiendo ciertos modelos de organización de las creencias (ver Bas, 1982), nos permite hablar de una organización o estructura de superficie y de otra estructura profunda. Las AM son accesibles a la introspección y constituyen la fachada de esa casa que llamamos estructura cognitiva. La organización profunda no es accesible a nuestra búsqueda activa, como no lo es el interior de una casa que miramos desde la calle. Está «ahí», pero sólo se manifiesta indirectamente a través de las AM. Está compuesta por las llamadas «creencias centrales o nucleares», que, como las normas de un código, han guiado sutilmente nuestras AM e incluso, a veces, la propia conducta manifiesta. Estas creencias centrales se deducen pues a través de un proceso de inferencia. En general, nosotros poseemos registros de las AM que el sujeto ha efectuado durante sus actividades diarias o al enfrentarse a una tarea difícil. A través de estos registros podemos inferir una o varias creencias centrales que, expresadas en forma de una breve proposición, nos permiten deducir aquellas AM que fueron registradas por el sujeto.

De todos modos, no todos los cognitivistas mantienen esos puntos de vista. Utilizar las AM como «signos» para inferir a partir de ellos la existencia de otras estructuras soporte resulta cuando menos formalmente innecesario. Los datos cognitivos pueden ser utilizados «tal y como se presentan» en la áctividad consciente, de modo similar a como hacen los conductistas ortodoxos respecto a la conducta manifiesta, sin establecer ningún tipo de inferencias sobre la existencia de supuestos estratos más profundos. La demanda de organizaciones subyacentes 
puede estar reflejando un «estilo» de interpretar la realidad, quizá muy propio del pensamiento tradicional, o bien puede ser requerida por las limitaciones propias del método objetivo. Así, estas estructuras deberían de hecho enunciarse, al menos, de dos maneras distintas. Por un lado, pueden revertir un simple interés instrumental y, por otro, presentarse como hipótesis que pretenden reflejar la realidad de los fenómenos. Algunos hallazgos de las teorías del aprendizaje nos permiten soportar la primera interpretación. Por ejemplo, los principios del condicionamiento semántico nos facultan para abordar la desensibilización de la respuesta emocional asociada con creencias irracionales o desadaptativas que «inferimos» de las AM del sujeto. Trabajando sólo con estas creencias ahorramos esfuerzo y tiempo, esperando que la generalización alcance a las AM concretas ofrecidas por el individuo. Una visión instrumental no categoriza esas creencias como «elementos» de la «estructura profunda» del sujeto. Aún más, la propia manifestación de sorpresa que, con frecuencia, suele acompañar a la reacción del sujeto ante el conocimiento de esas creencias básicas, puede hacernos sospechar que se trata de una «construcción ad hoc», efectuada a posteriori con fines de utilidad instrumental y sin que deba «reflejar» una realidad subyacente. De hecho, el individuo quizá no mantuvo nunca esas creencias, pero ha actuado o ha pensado «como si» las mantuviese. Lo único que sabemos es que la asociación semántica también «transmite» la excitación o inhibición emocional, y en ese sentido resulta más práctico intervenir sobre las ideas semánticamente inferidas que sobre todas y cada una de las registradas por el sujeto. El individuo pudo no haber hecho nunca el análisis inferencial que el psicólogo le presenta $y$, conscientemente, constituir para él una noticia nueva e incluso insólita. De modo que una cosa es que una «construcción» (el enunciado de la creencia básica) nos pueda resultar útil para resolver determinado problema y, otra, conferirle el carácter de realidad, y, además, de «realidad profunda». De hecho, estas «creencias básicas» podrían ser interpretadas como «rasgos» o «estilos cognitivos», cuando quizá no sean otra cosa que instrumentos útiles para la interpretación y la intervención. Los datos primarios son las AM que el sujeto registra o comunica verbalmente, todo lo demás, desde este punto de vista (y en la medida en que una inferencia, aunque sea de primer orden, no es un dato), es añadido o bien por requerimientos de significado, o de economía de interpretación, de pura y simple utilidad o por necesidades del propio método de intervención.

Por supuesto que también podemos suponer la existencia de estructuras profundas. Nada nos impide hacer inferencias de cualquier orden. Los únicos inconvenientes pueden derivarse de la credibilidad que ofrezcamos y de la adecuación a los métodos de trabajo socialmente aceptados, tales como el método científico. Por ejemplo, algunas investigaciones en el área de la percepción y del procesamiento de la información (Shervin y Dickman, 1980; Lundh, 1979), etc., nos permiten hablar de procesos y quizá estructuras no conscientes de las que todavía sabemos muy poco.

Otro problema es el del papel de las estructuras profundas inferidas en la causalidad de las cogniciones, emociones y conductas. Aquí es donde muestra cautela debe alcanzar un grado máximo. La posible aceptación de estructuras profundas no presupone, necesariamente, conferirles un papel fundamental en los mecanismos de causalidad. Los esquemas de causalidad «centralizada» o unidireccionales (como, por 
ejemplo, el psicoanálisis - subconsciente-, o el conductismo ortodoxo - ambiente-) no son capaces de explicar con el rigor necesario la compleja gama de la conducta humana, y las tendencias interaccionistas y bidireccionales no están exentas de ambigüedades (Fernández Ballesteros, 1983). Las estructuras básicas podrían ser constructos útiles para explicar ciertos fenómenos cognitivos y quizá mostrarse menos útiles para justificar algunas conductas manifiestas. Lo que un sujeto hace y lo que piensa no siempre resulta congruente, pero quizá alcanzase más coherencia en función de los presupuestos básicos inferidos del sujeto. En los momentos actuales, la compleja malla organizada en base a formulaciones empíricas (conductas, estímulos, relaciones funcionales objetivas, etc.), constructos (creencias, atribuciones, expectativas, intereses, etc.), inferencias desde los constructos (estructuras básicas, procesos subyacentes, estrategias, etc.) y variables biológicas y sociales hace extremadamente difícil el desarrollo de esquemas explicativos simples. El principio de parsimonia de Loyd Morgan no sólo continúa resultando conveniente, sino que parece imponerse aun cuando no sea formalmente necesario.

La mayoría de los terapeutas de orientación cognitivo-conductual comparten los diversos planteamientos anteriormente indicados, pero también difieren en la forma de encarar el cambio, en la génesis de las disfunciones y en los mecanismos específicos que las mantienen.

Vamos muy brevemente a comentar aquellas terapias que han considerado las AM de un modo central en la interpretación de los problemas y que han confeccionado instrumentos específicos de intervención sobre ellas. En este sucinto repaso haremos especial mención del fenómeno de la depresión, aunque también señalaremos otras áreas de disfunción. Posteriormente, presentaremos los métodos más utilizados para evaluar las AM y finalizaremos con una revisión más amplia de un método muy extendido para modificar un tipo de $A M$ especial: las autoinstrucciones, según lo han desarrollado Meichenbaum y otros y orientado hacia la problemática infantil.

El papel de las automanifestaciones en algunos modelos terapéuticos

\section{Las AM en el RET de Ellis}

En Ellis $(1962,1977)$ el origen de las AM irracionales es doble: a través del proceso de socialización o aprendizaje y por especiales tendencias innatas hacia lo irracional presentes en la mayoría de los seres humanos. Se mantienen mediante un mecanismo de autopropaganda. Los sujetos raramente se enfrentan a sus ideas irracionales poniéndolas en duda. Por otro lado, el concepto de irracionalidad está expresado claramente por Ellis: «Cualquier pensamiento, sentimiento o conducta que conduce a consecuencias contraproducentes y autodestructivas, que interfieren de forma importante con la supervivencia y felicidad del sujeto» (Ellis y Grieger, 1977, pág. 26). Pero ¿cuáles son las AM irracionales fundamentales? Ellis empezó à trabajar en este tema en 1955. Logró hacer una primera clasificación consistente en once creencias básicas. Posteriormente pudo encontrar tres creencias primarias de las que podían deducirse las anteriores. Son éstas: 
1. Tengo que actuar bien y tengo que ganar mi aprobación por mi forma de actuar, o de lo contrario me consideraré una mala persona.

2. Tú debes actuar de forma amable, considerada y justa conmigo, o de lo contrario eres un canalla, una mala persona.

3. Las condiciones en las que vivo deben seguir siendo buenas y fáciles, para que pueda conseguir prácticamente todo lo que quiero sin mucho esfuerzo e incomodidad, o de lo contrario el mundo se convierte en despreciable y la vida casi no merece ser vivida.

Este es el resumen de la filosofía de la «necesidad-perturbadora» recientemente expuesta (Ellis y Grieger, 1977).

El modo en que este autor trata de modificar las AM irracionales es a través del diálogo persuasivo y mediante ejercicios prácticos. La terapéutica de Ellis ha ido haciéndose con el tiempo más compleja, llegando a abarcar tanto técnicas conductuales como semánticas. La falta de una estructuración científica de la función de las AM irracionales en el desarrollo de las disfunciones ha sido apuntado recientemente (Eschenroeder, 1982), pero para Ellis esta observación no constituye ningún obstáculo insalvable ya que, en definitiva, nunca se propuso hacer del RET un método científico (Ellis, 1982).

\section{Las $A M$ en la terapia cognitiva de Beck}

A diferencia de Ellis (que habla de sistemas de creencias irracionales), Beck $(1963,1964,1967,1976)$ argumenta que los errores sistemáticos en el procesamiento de la información contribuyen al desarrollo y mantenimiento de las disfunciones cognitivas.

Desde el punto de vista del procesamiento, Beck distingue tres tipos de errores:

1. Pensamientos irracionales: dada una observación o premisa se falla en el proceso lógico de establecer conclusiones o inferencias. Por ejemplo, cuando generalizamos una conclusión soportada sólo por hechos restringidos.

2. Pensamientos no válidos: si bien el proceso lógico es correcto, el sujeto se basa en una información errónea o sesgada. Un ejemplo típico es el fenómeno de la atención selectiva.

3. Pensamientos disfuncionales: son aquellos que se mantienen en virtud de sus consecuencias, sin que tengan que ser irracionales o no válidos. Se podría ejemplificar este tipo de pensamientos recordando el modo en que inciden los pensamientos negativos sobre el resultado de un examen en un estudiante.

En cuanto al contenido, Beck distingue dos tipos de pensamientos:

1. Pensamientos automáticos: son pensamientos o imágenes que surgen en el flujo de la actividad mental, generalmente breves, y que para el sujeto reflejan la realidad. Son, por tanto, AM y, por ello, accesibles a la introspección.

2. Supuestos fundamentales: son como las reglas gramaticales. Uno las usa pero no las reconoce. Constituyen un conjunto de proposiones o creencias centrales en la organización cognitiva del sujeto (Rokeach, 1968), que no son accesibles a la introspección. Sólo pueden inferirse en base a un autoregistro muy preciso. 
¿Cuál es el origen de estas AM? Para Beck, tienen su fuente en el conjunto de las actitudes y experiencias que un sujeto ha adquirido durante su vida. Una vez asimilado un concepto concreto, éste puede influir en juicios posteriores y adquirir mayor firmeza. Por ejemplo, si un niño asimila la noción de que él es un inepto, bien por fracasos reales o porque sus padres le han señalado repetidamente sus errores, interpretará sus experiencias posteriores según esa idea. Cada vez que encuentre dificultades, tendrá tendencia a considerarse inepto. Así se crea un círculo vicioso alrededor de sí mismo: cada juicio negativo refuerza el concepto negativo de sí mismo, que, a su vez, facilita una interpretación negativa de su experiencia posterior, etc. Con la repetición, estos conceptos se convierten en estructurales, formando las estructuras latentes o el esquema cognitivo del sujeto (Beck y Shaw, 1981).

Los métodos para modificar estas AM son en Beck fundamentalmente inductivos, constituyendo el contraste con la realidad o prueba de hipótesis una de sus herramientas preferidas.

\section{Las AM en el modelo de autocontrol de Rehm}

El modelo de la depresión de Rehm $(1977,1981)$ no establece una clasificación especial del pensamiento; sin embargo, en función de la importancia que le atribuye a los déficit de autocontrol para explicar la génesis y el mantenimiento de este síndrome, se hace preciso incluir algunas notas aclaratorias. Rehm (1977), partiendo del modelo de autorregulación de Kanfer (Kanfer, 1970, 1971; Kanfer y Karoly, 1972), que contempla el autocontrol como un proceso por el que un individuo altera la probabilidad de una respuesta ante la relativa ausencia de soportes externos inmediatos, concluye que la depresión puede explicarse en función de seis déficit en el autocontrol de la conducta: «1) Observación selectiva de sucesos negativos; 2) Observación selectiva de las consecuencias inmediatas de la conducta frente a las consecuencias demoradas; 3) Rígido criterio autoevaluativo; 4) Atribución incorrecta de la responsabilidad; 5) Insuficiente autorrefuerzo; 6) Excesivo autocastigo.» (Rehm, 197, pág. 795.)

Para modificar activamente estos déficits se hace preciso algún tipo de evaluación de las AM. Por ejemplo, para modificar la atención selectiva sobre los sucesos negativos quizá fuera preciso que el sujeto registrase los sucesos positivos que le hayan podido ocurrir durante algún tiempo. Otro ámbito donde habría que registrar $A M$ sería aquel que nos lleva a un cambio en el estilo de autoatribución del sujeto. Suponemos que una observación más precisa de la covariación observada entre sucesos podría permitir la obtención de atribuciones más correctas.

Aun cuando el modelo de Rehm se nutre de elementos cognitivos (atención selectiva, atribución, autoevaluación, etc.), está más cerca de los modelos objetivos y operantes que la visión que sobre este tema han dado tanto Ellis como Beck.

\section{Las AM en el modelo de depresión de Seligman}

La reformulación de Abramson, Seligman y Teasdale (1978) sobre el «desvalimiento o desamparo aprendido», aplicado a la conducta humana, hace hincapié primeramente en los estilos de atribución del su- 
jeto y, posteriormente, en las expectativas que estos estilos crean. En primer lugar, las AM del sujeto se dirigen a buscar las causas de su desvalimiento (¿por qué me ocurre esto?, ¿qué falla en mí?, ¿qué puedo hacer para resolver mis problemas?, etc.). La percepción de la incontrolabilidad de los resultados, al margen de las respuestas dadas por el sujeto para ejercer su control, favorece, tras su repetición, una expectativa de «desvalimiento» que se generaliza desde el presente y el pasado hacia las experiencias futuras. Este sería el origen y el proceso de desarrollo de la depresión.

La intensidad de los síntomas depresivos guarda estrecha relación con el grado de convicción sobre la expectativa de desvalimiento y con la importancia personal del suceso desencadenador de la expectativa. El interés concedido por los formuladores de la teoría al nivel de autocredibilidad que el sujeto confiere a su expectativa, guarda una estrecha relación con el papel que, en general, puede ofrecer la variable «intensidad» en la explicación de ciertos fenómenos subjetivos y de la conducta (un primer ensayo para una formulación más extensa de la función que puede desempeñar queda ilustrada en Bas, 1982).

En cualquier caso, hemos de señalar que el paso desde un conjunto de atribuciones concretas de incontrolabilidad a una expectativa generalizadora ofrece, desde un punto de vista cognitivo, un doble análisis. Por un lado, la presencia de una sobregeneralización constituye una distorsión cognitiva que ya ha sido tipificada por otros investigadores en el ámbito de la depresión (Beck, 1976). Desde esta perspectiva, parece que la versión que presentamos hace un especial hincapié en un tipo singular de creencia (la expectativa de desvalimiento) y en un sólo error en el procesamiento lógico de la información (la sobregeneralización), dejando el resto de las distorsiones más frecuentemente encontradas (dicotomización, atención selectiva negativa, etc.) fuera de su modelo explicativo. En este sentido, sería deseable que el modelo formulase los mecanismos precisos a través de los cuales se pasa desde la sobregeneralización inicial al resto de los errores del proceso que solemos encontrar.

Otra objeción que se nos plantea procede del ámbito de la psicología experimental de la atribución. Así, por ejemplo, algunos trabajos como el de Covington y Omelich (1979), al estudiar la relación entre la atribución.y formulación de expectativas, han encontrado que las primeras sólo explican el 40 por 100 de la varianza de las segundas. Otros ingredientes, pues, al margen del estilo atribucional pueden estar gravitando en el mantenimiento de una expectativa de desvalimiento. Podríamos suponer, por tanto, que la sola percepción de la incontrolabilidad no parece dar cuenta del mantenimiento de la expectativa de fracaso en los seres humanos.

\section{Las $A M$ en el modelo de contracondicionamiento semántico de $M c$ Mullin y Giles}

Una orientación terapéutica que trabaja con las cogniciones, pero que no suele hacer interpretaciones al nivel de creencias irracionales, fallos en el procesamiento de la información o déficits de autocontrol, es la que se deriva de los trabajos pioneros de Eysenck (1957), Wolpe $(1958,1973)$ y Razran (1961). Por ejemplo, Mc Mullin y Giles (1981) utilizan las cogniciones del sujeto procedentes de los registros del mis- 
mo modo que lo haría cualquier otra orientación, pero se distinguen a la hora de establecer el paradigma de intervención. El que ellos utilizan es el de contracondicionamiento. Parten de los trabajos de Razran (1961) sobre el condicionamiento semántico que, como sabemos, acaba señalando que las respuestas emocionales de los sujetos se relacionan con el significado del mensaje, más que con su estructura morfológica. De este modo, una vez construido el mapa cognitivo o conjunto de creencias nucleares, se tratará de alterar las respuestas emocionales relacionadas con ellas, esperando que, por generalización, puedan ser eliminadas las respuestas emocionales asociadas con las creencias de superficie, es decir, aquéllas de las que el sujeto es consciente. La ICV ( «Inhibición cortical voluntaria») es una técnica de Mc Mullin y Casey (1975) parecida a la DS de Wolpe (1958) pero que utiliza AM de significado contrario a las creencias centrales en vez de imágenes. Para que estas AM contrarias lleguen a ser eficaces deben reunir, según los autores, ciertas características (Mc Mullin y Giles, 1981). A saber: 1) Deben ser directamente opuestas a las creencias del sujeto; 2) Deben ser manifestaciones creíbles de la realidad; 3) El sujeto debe desarrollar tantas AM contrarias como sea posible; 4) Las AM contrarias necesita crearlas el propio sujeto; 5) Necesitan ser precisas y fáciles de recordar; 6) El individuo debe aplicárselas con asertividad, agresividad e intensidad emocional.

Previamente, los sujetos deben llegar a la conclusión de que sus creencias nucleares son científica u objetivamente falsas, al margen de que continúen sintiéndolas como verdaderas. El procedimiento tiene como base el trabajo intensivo, diario y resulta bastante sistemático y racional.

\section{Métodos para evaluar las automanifestaciones}

La clasificación de las variables cognitivas ha tenido recientemente diversas formulaciones (Kendall y Kogerski, 1979; Fernández Ballesteros, 1981; Landau y Goldfried, 1981; Mischel, 1981b; Kendall y Braswell, 1982). La codificación de las distintas cogniciones en un amplio número de categorías y dimensiones de evaluación no ha de extrañarnos. Aún aparecerán más debido a la complejidad del campo que tratamos. Lo importante es investigar intensamente para desarrollar su accesibilidad, así como el valor psicométrico y la utilidad de los instrumentos que utilicemos. Las AM resultan una de las categorías más comunes en las clasificaciones anteriormente citadas. Por otro lado, constituyen la materia prima de la que se pueden deducir otras creencias, atribuciones, expectativas, planes y metas, etc.

El estudio de las AM puede orientarse hacia distintos fines, por ejemplo:

1. Examinar la relación entre AM y conducta, sentimientos o experiencias manifiestas.

2. Investigar el papel de las AM en el desarrollo de distintas formas de psicopatología y en los procesos de coping.

3. Confirmar que una terapia orientada a modificar las AM produce los resultados positivos esperados.

4. Estudiar el efecto de la manipulación de distintas AM en los sujetos, etc. 
Los distintos procedimientos que se han utilizado para registrar las AM podrían resumirse fundamentalmente en cuatro: 1) Métodos de registro; 2) Métodos de comprobación; 3) Métodos de producción; 4) Métodos de muestreo. Tratemos de ofrecer las características más relevantes de cada uno de estos métodos.

\section{Métodos de registro}

En este procedimiento los registros pueden hacerse de dos formas: a) De modo discreto o velado y b) siguiendo ciertas instrucciones dadas por el experimentador. Generalmente, una vez hecho el registro, las AM se codifican según ciertas categorías (habla autodirigida, sobre la tarea, irrelevantes, positivas, negativas, etc.).

Uno de los instrumentos más utilizados para el primer tipo de registro es el espejo unidireccional. Un ejemplo de aplicación podemos encontrarlo en el trabajo de Copeland (1979) que estudió el habla espontánea de niños hiperactivos. Una conclusión (que va en la línea de otros comentarios que haremos más adelante) consistió en descubrir que estos niños daban más descripciones de sí mismos que del plan de la tarea, en comparación al grupo de niños normales. Pero resulta interesante hacer una serie de comentarios del registro del habla espontánea, como son: 1) No hablar no indica no pensar; 2) La suspicacia o estar a la defensiva pueden inhibir las verbalizaciones; 3) La mayor parte del habla registrada por este procedimiento no es autodirigida (habla idiosincrática), y 4) El problema general de tener que inferir desde el habla manifiesta a los procesos encubiertos.

En el segundo procedimiento, el investigador invita al sujeto a que diga los pensamientos que ha tenido durante la presentación de una escena. Después, como siempre, se clasifican en categorías. Un ejemplo de este procedimiento es el trabajo de Craighead, Kimball y Rehak (1979), en donde se comprobó la relación entre necesidad de aprobación social y AM negativas. Una variante de este procedimiento consiste en invitar al sujeto a que "piense en voz alta» mientras realiza la tarea. Un inconveniente de este método es el «efecto reactivo» que tiene el pensar en voz alta y que afecta al flujo de las verbalizaciones, especialmente cuando los sujetos saben que están siendo evaluados. Otra variante fue utilizada por Meichenbaum (1975) en donde al sujeto se le pasaba un video con la secuencia de las tareas que había realizado y el investigador le invitaba a referir los pensamientos que le acompañaban durante la realización de esa tarea.

\section{Métodos de comprobación}

Este método consiste en pasar unos inventarios después de que el sujeto ha llevado a cabo una tarea, a fin de que señale los pensamientos particulares que ha tenido y su frecuencia. Este procedimiento ha sido ampliamente utilizado en áreas tales como asertividad, estrés, depresión, ansiedad, autocontrol y problemas de interacción social. Debido al reciente desarrollo de algunos cuestionarios de gran interés clínico vamos a hacer hincapié en los procedimientos que se han seguido para su confección. Los items de que están compuestos los inventarios han sido confeccionados utilizando dos procedimientos distintos. En un 
caso se ha utilizado un conjunto de individuos (normalmente estudiantes) o clínicos como jueces. En otros casos se ha procedido a comparar grupos, uno de los cuales se había seleccionado según un criterio preestablecido. Entre los inventarios obtenidos por el primer procedimiento figuran el de Schwartz y Gottman (1976) sobre asertividad (ASST), en donde los jueces fueron estudiantes y los ítems seleccionados aquellos en donde hubo un acuerdo en el 90 por 100 de los casos. Otros ejemplos podemos encontrarlos en el inventario de Kendall y colaboradores (1979), que evalúa los pensamientos de sujetos que van a ser intervenidos quirúrgicamente (SSI); en el de Glass et al. (1982), confeccionado para estudiar las habilidades heterosexuales; en el de La Pointe y Harrel (1978), diseñado para investigar la relación entre pensamientos y sentimientos y en el de Mahoney y Avener (1977), elaborado para definir el estilo cognitivo de los atletas, entre otros.

El segundo procedimiento utilizado para seleccionar los items ha sido a través del uso de grupos. De esta manera se ha confeccionado el «Cuestionario de Pensamientos Automáticos» (ATQ-30) de Hollon y Kendall (1980), en donde a un grupo de 800 estudiantes se les invitó a que escribiesen los pensamientos que tenían cuando se sentían deprimidos. En base al BDI (Beck et col., 1961) y a la escala D del MMPI, se seleccionaron los grupos criterio de depresivos y no depresivos y se entresacaron los items que diferenciaban significativamente a un grupo de otro. Los items finales del grupo depresivo se validaron con otro grupo criterio. Otro inventario para evaluar la ansiedad (ASSI) fue llevado a cabo por los mismos autores con este procedimiento.

\section{Métodos de producción}

Este método consiste en hacer que los sujetos escriban los pensamientos («Listado de Pensamientos») que han tenido durante una tarea experimental previa. Después se les invita a que los incluyan en una serie de dimensiones de autoevaluación (favorables hacia sí mismos, desfavorables, neutros, etc.). Es el método más utilizado, y ha sido empleado como variable dependiente para evaluar los resultados de la terapia.

Una dificultad de este método surge a la hora de establecer adecuadamente las dimensiones de autoevaluación. Categorías limitadas puedan reducir las posibles conclusiones y caregorías amplias pueden dar conclusiones redundantes.

Cacioppo, Glass y Merluzzi (1979) han utilizado este método para estudiar las respuestas cognitivas en ansiedad heterosexual. También se ha aplicado al estudio de las respuestas cognitivas ante apelaciones persuasivas, etc.

\section{Métodos de muestreo}

Se trata de recoger al azar, durante el día, distintas muestras de pensamientos a través de un instrumento que le avisa al sujeto el momento en que debe recogerlos. También puede hacerse en circunstancias determinadas del día, en un diario, pudiendo registrarlos o responder a cuestionarios o escalas. Esta última modalidad es la más utilizada. Se puede aplicar en el laboratorio y en el entorno natural. 
Klinger (1978) aplicó este método para evaluar pensamientos durante un examen y Hurlburt (1979) lo utilizó en el entorno natural para registrar pensamientos y conductas durante la vida diaria.

\section{Consideraciones generales sobre los distintos métodos}

\section{Confiabilidad}

En relación al método de comprobación, se aprecia una falta de datos. La excepción se da en el cuestionario ATQ-30 en donde la correlación test-retest fue de 0,92 y los cambios en los síntomas depresivos fueron consistentes con los cambios en el ATQ-30. Respecto al método de producción se da la misma circunstancia de falta de datos, aunque algunos autores (Kendall y Hollon, 1981) se refieren a estudios en donde puede encontrarse una correlación entre jueces de 0,95 , lo que supone una alta valoración de este procedimiento para evaluar AM.

En el método de muestreo, al margen de la dificultad general de tener un control de los registros (sobre todo cuando se efectúan en el entorno natural), algunos estudios de confiabilidad en la codificación de los pensamientos han ofrecido correlaciones elevadas (de 0,8 a 0,9 ).

\section{Validez}

Como es obvio, no hay ninguna posibilidad de verificar las congniciones registradas en los informes, ni la exactitud de las transcripciones. En definitiva nos plegamos a la impresión de Lieberman (1979): «El último criterio para la evaluación de cualquier forma de dato introspectivo debe ser su utilidad para predecir conductas futuras.»

Ventajas e inconvenientes de cada método

- El Método de Registro ofrece una riqueza de habla espontánea que no está limitada, por ejemplo, por los items de un inventario, pero puede inducir una conducta defensiva o de precaución en el sujeto.

- El Método de Comprobación puede ser menos reactivo, no requiere codificación subsiguiente para introducirlo en categorías y posibilita fácilmente su cuantificación, pero puede sufrir el problema del autoinforme retrospectivo.

- El Método de Producción probablemente ofrece un rango más amplio de información.

- El Método de Muestreo tiene las ventajas de no utilizar datos retrospectivos y, por tanto, de obviar el olvido, la imprecisión o los errores de interpretación. En contra, este método puede provocar reacciones ante las señales de aviso del aparato electrónico difíciles de precisar.

\section{Método y contenido}

No hay que confundir el contenido cognitivo específico que deseamos medir con el método empleado. Un mismo método puede servirnos para medir distintos contenidos, y, en general, los instrumentos existentes para medir distintos fenómenos encubiertos (atribuciones, creencias, expectativas, etc.), son, con distinto nivel de especificidad, apropiados para evaluar el habla autoreferente. Por ejemplo, distintos 
métodos podrían ser utilizados para evaluar los diversos contenidos expresados en el siguiente ejemplo dado por Kendall y Hollon (1981): «Un sujeto puede imaginar una situación interpersonal, creer que se conducirá inadecuadamente, atribuir esa expectativa a la carencia de habilidades interpersonales, e iniciar un diálogo interno consistente en el predominio de automanifestaciones negativas.»

\section{La accesibilidad de las $A M$}

La accesibilidad a los datos en cualquier empresa de investigación científica resulta una cuestión básica. Apenas podríamos hablar de validez o fiabilidad si los datos de que partimos no fueran de algún modo aprehensibles, mínimamente percibidos o autopercibidos. Recientemente, Nisbett y Wilson (1977) llegaron a la conclusión de que la simple introspección no es suficiente para garantizar una información confiable o correcta. Pero tras una larga discusión (ver Smith y Miller, 1978; Lieberman, 1979; Ericsson y Simon, 1980; Kendall y Hollon, 1981), se ha llegado a establecer un acuerdo en donde si bien se acepta la accesibilidad en general, es preciso puntualizar en cada caso el tipo de cognición que se desea evaluar y la presencia de posibles disfunciones o psicopatologías (Kendall y Kogerski, 1979). Se da, por tanto, una accesibilidad diferencial según los casos.

Pero necesitamos distinguir también entre la accesibilidad de las AM y la de ciertos tipos de inferencias. A veces, como señalábamos al principio del escrito, algunos autores parecen confundir por ejemplo AM y creencia central. Una AM puede quizá estar «reflejando» una creencia central, pero no constituir una creencia importante en sí misma. En esos casos, la AM puede ser accesible, pero la inferencia es siempre una construcción lógica a posteriori, que, en general, requiere la aceptación explícita del sujeto. Aún más, la aceptación por el sujeto no puede ser considerada como la piedra angular de su validación (cuestión a veces pasada por alto en la práctica clínica). Sólo en la medida en que nos sea útil para predecir y modificar futuras conductas y $A M$ podremos decir que la inferencia cumple un papel científico. Así, estas inferencias actúan como hipótesis explicativas, que deben ser evaluadas, confirmadas o rechazadas en la práctica. El acceso a estas hipótesis (por parte del propio sujeto) presenta problemas peculiares que se distinguen de aquellos otros que caracterizan el acceso a las AM ordinarias. Por ejemplo, en el caso de las creencias básicas, el sujeto puede rechazarlas por apreciar que entran en conflicto con ciertas conductas suyas, o porque serían socialmente reprochables, etc. La accesibilidad de las atribuciones puede parecer más fácil, y a veces es así, pero en ocasiones también requiere procesos inferenciales ya que en definitiva se trata de un tipo peculiar de creencias. La mayor o menor dificultad para expresar verbalmente los propios pensamientos, o para describir las imágenes suelen ser otras dificultades complementarias.

La accésibilidad diferencial no sólo varía según el tipo de cognición, sino que se ve afectada por la psicopatología. En la ansiedad y la depresión, solemos encontrar fallos en la concentración y en la memoria a corto plazo. Los "pensamientos automáticos» (Beck, 1976) en la depresión y en la manía pueden presentarse de modo tan fugaz que el sujeto puede encontrar serias dificultades para poder registrarlos con precisión. Otras alteraciones (impulsividad cognitiva, alteraciones del 
lenguaje, obsesiones, esquizofrenia, etc.) presentan a su vez sus correspondientes dificultades de accesibilidad. Estos factores han de tenerse en cuenta a la hora de llevar a cabo la práctica clínica, si esperamos trabajar con datos mínimamente confiables.

En cuanto a los métodos de registro, parece evidente que algunos procedimientos deben favorecer la accesibilidad mientras que otros quizá la interfieran. El método de registro diseñado por Davison, Robin y Johnson (1983) debería favorecer la accesibilidad dada la corta duración de la presentación de la situación-problema y la rapidez con la que se registra la respuesta. También los métodos de comprobación pueden facilitarla, al actuar los items del cuestionario como estímulos evocadores (aunque esto puede acarrearnos otros tipos de problemas), etcétera.

El tema de accesibilidad de los fenómenos cognitivos es viejo, pero, en cambio, presenta grandes lagunas en su investigación.

\section{Requisitos para un buen registro}

Recientemente Davison, Robin y Johnson (1983) han señalado que para que un paradigma de registro fuese satisfactorio debería poseer ciertas características:

1. Debería permitir que la respuesta verbal reflejase, del mejor modo posible, el proceso de pensamiento actualmente en marcha, mejor que un informe retrospectivo.

2. Los sujetos deberían verse lo menos constreñidos posible acerca de lo que informan, y poder efectuar su informe del modo más fácil posible y sin demora.

3. El experimentador debería estar capacitado para especificar y manipular la situación en la que los sujetos están respondiendo, a la vez que debería poder presentar sucesos suficientemente realistas y complejos.

4. Las situaciones presentadas deberían ser tanto del tipo de las que no crean problemas o dificultad al sujeto como aquellas otras capaces de producir ansiedad.

5. Finalmente, el procedimiento no debería ser prohibitivo en tiempo y coste.

Estos autores han propuesto un sistema que, por su simplicidad, vamos a explicar muy brevemente. Se crea y se registra una conversación que simula un suceso complejo. Se les invita a los sujetos a suponerr que el suceso está ocurriendo actualmente y que ellos son parte de la situación. Se les dice que estamos interesados en la clase de pensamientos y sentimientos que experimentan mientras transcurre la situación. Durante un breve intervalo de 15 a 25 segundos, se les hace escuchar el registro, seguido de un silencio de 30 segundos, durante el cual los sujetos dicen lo que han pensado o sentido. Se presenta otro intervalo de grabación, seguido por el informe del sujeto y así una y otra vez. Estas verbalizaciones son grabadas para ulterior análisis. Al procedimiento se le ha denominado con las siglas ATSS ( «Pensamientos articulados durante situaciones simuladas»). 


\section{Aplicaciones de una automanifestación especial:}

\section{Las autoinstrucciones}

Las autoinstrucciones (AI) son una forma particular de automanifestaciones (AM). El Diccionario de la Real Academia Española señala que las instrucciones pueden significar «un conjunto de reglas $o$ advertencias para algún fin». Cuando es el propio individuo el que se aplica esas reglas y persigue ciertos fines, podemos hablar de que se está impartiendo autoinstrucciones (AI).

Las AI pueden ser inducidas desde fuera de nosotros o surgir como fenómenos que proceden de nuestros aprendizajes previos. Pueden servir para conducir o regular una cadena semántica de razonamientos, ajustándonos a un plan preestablecido de reglas o hitos que marcan el rumbo o señalan el contenido al que hay que adaptarse en cada momento a lo largo del discurso. Pero también pueden adquirir un carácter instrumental, y colocarse al servicio de la acción. ¿Nos pueden ayudar nuestras automanifestaciones (es decir, aquello que nos decimos a nosotros mismos) a modular o regular más eficazmente una tarea manifiesta?, o, por el contrario, ciertos tipos de AM ¿podrian interferir en la ejecución? La idea de colocar el «lenguaje interno» al servicio de objetivos «voluntarios» resulta algo extraña en nuestro contexto cultural. La mayoría de nosotros siempre hemos imaginado, en algún momento, que el autolenguaje era algo «autónomo», que obedecía a reglas intrínsecas difícilmente «manejables» y su contenido debía estar gobernado por instancias «superiores» (reglas lógicas, morales, religiosas, etc.). Una expresión del tipo: «pon el pensamiento o el lenguaje a tu servicio, como lo están tus manos o tus pies», correría el riesgo de ser rechazada por la mayoría de nuestros conciudadanos. Se nos ha dicho que el pensamiento o el lenguaje están al servicio de la «verdad», de la «sinceridad», incluso de la «salvación».

El pensamiento occidental ha recalcado la necesidad de poner estos fenómenos bajo la tutela de las creencias e intereses que prevalecían en cada época histórica. Podrían ser las creencias religiosas, las políticas o los intereses económicos, pero no conozco ninguna época en la que se señalase la conveniencia de situar estos pensamientos bajo el control del deseo libre de cada sujeto, respetando ese autocontrol y potenciándolo deliberadamente. No es el lugar ni el momento para que yo haga aquí una revisión crítica de este problema. Pero sí desearía señalar en una brevísima pincelada lo que podríamos calificar como el «discurso del poder» en las deontologías tradicionales. Este discurso estaría compuesto por una serie de creencias fundamentales. Serían éstas:

1. La conducta está primordialmente dirigda por el pensamiento. El ambiente y la historia del sujeto son secundarios, y, en cualquier caso, sus influencias pueden ser superadas por un acto de «voluntad».

2. El pensamiento en general, pero muy especialmente aquel vinculado a la acción debe estar regido por «normas superiores» (bien de origen divino - normas morales - o bien de origen humano - conducta racional-). El poder puede así tener un origen divino o un origen popular. En cualquier caso, la obligación del individuo consiste en someterse a sus dictados.

3. De lo anterior concluimos que lo que se hace está al servicio de lo que se piensa, y lo que se debe pensar está, en última instan- 
cia, más allá de mis deseos y control, especialmente cuando se vincula a la acción.

4. Lenguaje y pensamiento se hallan relacionados. Controla el pensamiento (creencias básicas) y atarás también el lenguaje y su poder evocador de conductas.

¿No es todo esto pragmatismo, pragmatismo de «orden superior»? Se traslada el control de mí mismo a un «orden» constituido por el conjunto de los «valores superiores», normalmente de carácter absoluto. Bien, pues un intento de trasladar de nuevo el control a las manos del individuo lo constituye la teoría del autocontrol. Si bien en Psicología solemos hablar de temas de autocontrol refiriéndonos a individuos concretos en situaciones concretas, el potencial heurístico del término podría ir mucho más allá, hacia contextos sociales e ideológicos.

Con este supuesto, es decir, bajo la hipótesis de que el lenguaje puede influir en la conducta, se han iniciado hace algunos años una serie de trabajos que tratan de verificar empíricamente este aserto. El estudio de las variables que intervienen y la posibilidad de que el individuo las use activamente para mejorar su conducta y sus emociones constituye el centro de atención de las investigaciones.

Entre las distintas formas con las que los mediadores verbales pueden afectar a nuestra conducta, podemos elegir una modalidad relativamente fácil de manejar como son las AI y ver si obtenemos los efectos esperados sobre la conducta. El esquema básico sería, pues, utilizar como variable independiente lo que un sujeto se dice a sí mismo en forma de AI, y, como variable dependiente, los cambios esperados en la tarea que podrían ser atribuidos funcionalmente al uso de las AI.

Uno de los investigadores que más tiempo le ha dedicado a este asunto ha sido Meichenbaum (1969, 1973, 1974, 1977, 1979). Veamos de analizar el procedimiento, especialmente en sus aspectos prácticos, y tratemos finalmente de evaluar sus resultados.

\section{Origen y trabajos previos del Entrenamiento en Autoinstrucciones (EAI)}

Luria (1961) asume que las funciones del «segundo sistema de señales» (lenguaje) trascienden las leyes del condicionamiento estímulorespuesta. El lenguaje altera la percepción, actúa para concretar las relaciones temporales y está en la base de la interacción inteligente con el mundo.

Según este investigador la aparición del control voluntario de las conductas sigue tres etapas de desarrollo:

1. Entre los dos y tres años, las palabras dirigidas al niño actúan como estímulos condicionados, empujándole a la acción, pero sin un carácter de significado.

2. Entre los cuatro y cinco años, el habla auto-dirigida del niño llega a ser ccapaz de iniciar o inhibir la conducta, dentro de un sistema analítico de conexiones significantes.

3. Finalmente, por los seis o siete años, el habla privada, silenciosa, llega a ser dominante y asume el papel de auto-gobierno.

Podríamos añadir que, con la práctica, los pensamientos se reducen, 
Si bien los límites temporales han sido discutidos por otros autores, la secuencia ha sido utilizada por Meichenbaum (1974) para diseñar un programa de entrenamiento en autocontrol por medio del lenguaje (AI).

Una serie de trabajos previos (Muray, 1938; Galperin, 1969; Kelin, 1963; Bam, 1967, y otros) habían puesto de manifiesto la manera con que las autoverbalizaciones afectan a la conducta. Por otro lado, Jensen (1966) había dado una buena definición de mediación verbal que encajaba con los propósitos de Meichenbaum. La había definido así:

«La mediación verbal consiste en hablar con uno mismo de manera pertinente cuando nos enfrentamos con algo que queremos aprender, un problema que queremos resolver, o un concepto que queremos alcanzar. En los adultos, el proceso generalmente llega a ser bastante automático e implícito; sólo cuando un problema es bastante difícil empezamos a pensar en voz alta. La mayoría de los procesos mediacionales tienen lugar subvocalmente, por debajo de nuestro nivel de conciencia» (pág. 101).

Los trabajos de Kohlberg et. col. (1968) sobre el desarrollo jerárquico del lenguaje interiorizado, que da lugar a una organización en varios niveles, también afectó a su diseño del entrenamiento en AI.

La observación de Luria (1959) y otros ẹn el sentido de que los niños biperactivos tenían una falta de eficiencia en las tareas verbales, le llevó a desarrollar un procedimiento de AI que constaba de las siguientes fases:

1. Un adulto (modelo) desarrolla una tarea mientras habla consigo mismo en voz alta.

2. El niño ejecuta la misma tarea bajo la dirección de las instrucciones del modelo.

3. El niño realiza la tarea mientras se da instrucciones a sí mismo en voz alta.

4. El niño se repite las instrucciones en voz baja a medida que va realizando la tarea.

5. El niño realiza la tarea mientras guía su ejecución a través del lenguaje interiorizado.

Vemos cómo estas fases reflejan fielmente los pasos del control voluntario de la conducta propuestos por Luria (1961).

Un ejemplo de modelado cognitivo en donde un sujeto intentaba copiar un dibujo había sido así: "¿Qué tengo que hacer? Quires que copie el dibujo; tengo que hacerlo despacio y cuidadosamente. Dibuja esta línea hacia abajo, abajo, bien, después a la derecha, esto es, ahora otro poco hacia abajo y a la izquierda, bien, lo estoy haciendo bien. Recuer$\mathrm{da}$, hazlo despacio. Ahora vuelve otra vez. Aunque cometa un error debo ir despacio y con cuidado. Bien, tengo que ir ahora hacia abajo. Acabé. Lo hice» (Meichenbaum, 1977, pág. 32).

La aplicación del procedimiento en tareas sucesivamente más complejas dio lugar a una mejoría postratamiento en los instrumentos de evaluación utilizados (laberinto de Porteus, CI de WISC y en el test de emparejamiento de figuras familiares -MFF).

La estrategia fundamental consiste en interrumpir la secuencia de conductas y pensamientos que preceden a la respuesta desadaptativa y producir autoafirmaciones e imágenes incompatibles con ella. Se trata de conseguir que las conductas desadaptativas que son habituales y naturales (no premeditadas) sean primero convertidas en desautomatiza- 
das, es decir, sean precedidas por cogniciones premeditadas. Así, las mediaciones forzadas aumentan la probabilidad de interrumpir las cadenas de pensamiento, conductas o imágenes que llevarían a la respuesta desadaptativa. Por todo esto, el modelo debía presentar ciertas habilidades, tales como: 1) Definir el problema: ¿Qué tengo que hacer?; 2) Concentración en la tarea y respuestas de autodirección: «Cuidadosamente... dibuja la línea hacia abajo»; 3) Autorrefuerzo: «Bien, lo hago bien»; 4) Habilidades de autoevaluación y corrección de errores: «Eso está bien... aunque cometa un error debo ir despacio».

\section{Variables personales y EAI}

Algunos estudios se han orientado a buscar las características personales de los niños con mejor prognosis para recibir entrenamiento en autoinstrucciones. Copeland (1981) encontró que variables como la atribución interna de causalidad, nivel verbal elevado, alto cociente de inteligencia, uso más frecuente de habla privada, bajo nivel de actividad motora y buena relación con el terapeuta, constituían factores que favorecían el éxito en el entrenamiento con niños impulsivos. También la edad es un importante factor a tener en cuenta. Las instrucciones explícitas y concretas resultan mejores que las instrucciones abstractas para niños de seis y siete años (Meichenbaum y Goodman, 1969; Meichenbaum, 1975; Denney, 1975). En cambio, para edades entre ocho y doce años, la instrucción conceptual resulta más útil (Kendall y Willcox, 1980).

Ridberg, Darke y Hetherington (1971) encontraron que la combinación de señales verbales y no verbales era positiva en niños con un CI bajo, pero parecía interferir en los procesos mediacionales de los niños con un CI alto. Esto nos lleva a la consideración más amplia de que el entrenamiento en autoinstrucciones puede ayudar a aprender una nueva tarea, pero puede interferir si esa tarea ya se conoce.

La pertinencia de estas variables personales en los niños normales para optimizar el rendimiento en el tratamiento, fue analizada por Copeland y Hammel (1981). Los resultados no ofrecieron diferencias significativas entre el grupo experimental y el grupo control.

\section{Aplicaciones}

Este procedimiento y su estrategia de base ha sido aplicado a varios tipos de problemas y al desarrollo de habilidades específicas. Podemos citar varios ejemplos de aplicación en el área infantil:

a) En el estudio de la actividad no productiva y de alteración en clase (Bornstein y Quevillon, 1976).

b) En la alteración de hábitos de engaño para niños de jardín de infancia y los primeros grados de enseñanza (Monahan y O'Leary, 1971).

c) Estudios sobre latencia de respuestas y errores en niños normales en el FFT (Bender, 1975; Meichenbaum y Goodman, 1971).

d) La ejecución del laberinto de Porteus (un test que mide habilidades de planificación y estilo cognitivo) en niños hiperactivos, fue estudiada por Palkes, Stewart y Freedman (1972) y por Palkes, Stewart y Kahana (1968). 
e) La concepción del ritmo en niños con problemas emocionales fue analizada por Finch, Wilkinson, Nelson y Montgomery (1975).

f) En la tolerancia a exposiciones prolongadas a la oscuridad total en niños de cinco y seis años (Kanfer et al., 1975).

g) Estudios de las latencias de respuesta en situaciones donde se presenta una tentación para distraer la atención de la tarea (Harting y Kanfer, 1973; Patterson y Michel, 1976).

h) Análisis sobre el estilo de pensar y de conducirse de niños cognitivamente impulsivos (Douglas et col., 1976; Dickie, 1973).

i) La relación entre el lenguaje interiorizado y el estilo conductual en niños agresivos fue analizada por Camp (1977) y por Camp et col. (1977).

j) El valor pedagógico del EAI ha sido investigado por Karnes et col. (1970) y se pueden encontrar revisiones interesantes sobre la educación y la instrucción en Meichenbaum y Asarnow (1979) y en Borkowski y Cavanaugh (1978).

k) En el área de la conducta académica, además del estudio de la resistencia a la tentación, se ha estudiado la demora de la gratificación (Mischel, 1974, 1981, 1981a), la solución de problemas (Stone, Hinds y Schmidt, 1975; Spivack y Shure, 1974, etcétera.), la lectura (Brown, .1977; Ryan, 1981) y la creatividad (Goor y Sommerfeld, 1975; Henshaw, 1977, etc.).

1) En niños tímidos o socialmente aislados (Gottman, Gonson y Rasmussen, 1974; Jabichuck y Smeriglio, 1976, etc.).

m) Una aplicación de interés actual ha consistido en comprobar la forma en la que las AI pueden mejorar el entrenamiento para tocar instrumentos musicales (Gruson, 1980).

\section{Aportaciones al conocimiento de otras áreas}

Las aportaciones al conocimiento de algunas áreas de problemas ha sido positiva gracias a la aplicación de los procedimientos de AI. Veamos algunos ejemplos en la impulsividad y la agresividad:

a) Douglas (1972) comprobó que los niños impulsivos presentaban un déficit en "parar, mirar, escuchar y pensar», fuera cual fuera la modalidad de estimulación (visual, auditiva, visual-motora o kinestésica) utilizada.

b) Que los niños impulsivos tenían menos control verbal de la conducta no verbal que los niños reflexivos (Meichenbaum y Goodman, 1969).

c) Que los niños reflexivos usaban su lenguaje egocéntrico de forma más madura, más instrumental y más autodirigida que los impulsivos (Meichenbaum, 1971).

d) Camp et col. (1976) comprobaron en niños agresivos que tenían las mismas capacidades verbales que los normales, pero se distinguían de ellos en que no inhibían la primera respuesta.

e) El resumen de los déficit de ejecución que presentan los niños cognitivamente impulsivos llevó a Meichenbaum (1977) a presentar las siguientes conclusiones:

1. Estos niños no pueden comprender la naturaleza del problema, y, por tanto, no pueden saber qué mediadores tienen que producir: comprensión deficiente. 
2. Pueden tener en su repertorio los mediadores correctos; pero pueden fallar al producirlos espontánea y apropiadamente: producción deficiente.

3. Los mediadores que producen pueden no guiar su conducta: deficiencia mediacional.

\section{Observaciones prácticas en la aplicación del EAI}

Algunas observaciones prácticas a la hora de implantar el entrenamiento en autoinstrucciones podrían ser las siguientes:

a) Iniciación a través del juego, con historias de representación en donde no se presentan fallos ni frustraciones.

b) Modelar el enfrentamiento a los fallos.

c) Asegurarse de que el niño no repite las AI de manera mecánica y automática, sino con afectividad (inflexiones de voz) y comprensión del significado de la tarea.

d) Las AI deben adaptarse al niño de manera flexible. Pueden eliminarse, acortarse o alargarse etapas según las posibilidades del niño.

e) Utilizar el principio de las aproximaciones sucesivas, fragmentando aquellas atareas que sean más complejas.

f) «Pensar en voz alta» si, pero «hablarse a sí mismo», no (les recuerda a los locos).

g) Usar las imágenes junto con la conducta manifiesta y el lenguaje. Por ejemplo, Mischel (1974, 1981, 1981a) comprobó que la imaginación es utilizada de distinto modo, como un instrumento para enfrentarse con la tentación, según la edad de los niños. Esta evolución en las estrategias puede usarse si es preciso. La imagen de una tortuga en los niños impulsivos medió favorablemente para reducir el número de fallos. Así, una técnica (Schneider y Robin, 1975) para interferir en las respuestas agresivas de enfado o en la frustración es la de «hacerse la tortuga». Cuando el niño experimenta alguno de estos sentimientos se «mete en el caparazón, se relaja, hace ejercicios de AI y resuelve el problema».

h) El niño debe colaborar a la hora de discutir los propósitos de la tarea, la mejor estrategia a seguir y cómo llevarla a efecto.

i) Para los niños (incluso los más pequeños) se les facilita la tarea de verbalizar si se les pregunta por el «qué» más que por el «cómo» o el «por qué» hizo esto o lo otro. Además deben eliminarse los objetos de su vista, de lo contrario los utilizarán para la explicación en vez de hacerla verbalmente.

j) Un ejemplo para registrar las verbalizaciones espontáneas de los niños pequeños es un juguete ( $\mathrm{E} l$ señor payaso»), que lleva incorporada una cinta con instrucciones ( Oye, tengo unas enormes orejas y me encanta que los niños me las llenen con todo lo que piensan y sienten, sea lo que sea») y una cinta grabadora (Mischel, 1975).

k) Cuando intervienen los profesores en el programa, resulta conveniente que modelen «pensando» en voz alta. Pueden hacerlo de dos maneras, o modelando directamente las cogniciones requeridas para la tarea o bien aportar cogniciones a través de las cuales el niño puede descubrir por sí mismo qué es- 
trategia emplear. El uso de «metarreglas», es decir, el «aprender cómo aprender», inducir principios a través de los cuales puedan deducirse reglas, constituye el objetivo actual de las investigaciones sobre AI. Pero sobre ello hablaremos más adelante.

1) El entrenamiento en babilidades de solución de problemas (Spivack, y Shure, 1974; Stone, Hinds y Schmidt, 1975), en donde al niño se le invita a imaginar los medios necesarios para obtener ciertos fines, a formular distintas alternativas posibles ante un problema dado y a adelantar las posibles consecuencias junto con su evaluación, constituye un componente muy frecuente en los programas de entrenamiento.

m) No hay que olvidar que existen trabajos que demuestran que las AI no añaden eficacia a un modelado cognitivo cuando trabajamos con niños normales. En cambio, con niños impulsivos ya Meichenbaum y Goodman (1971) y Neider (1971) pudieron demostrar que disminuía el número de errores y aumentaba la latencia de respuesta.

n) Una observación muy importante a la hora de llevar a cabo la fase de modelado es la de que un modelo de «coping» (aquel que comete fallos y experimenta frustraciones y muestra el modo con que los supera) es mejor que un modelo «mastery» (aquel que no comete errores). Los terapeutas, los profesores y los padres no deberían olvidar este importante aspecto del aprendizaje por modelado.

\section{La utilización de otros componentes en el EAI}

En cualquier entrenamiento en autoinstrucciones suelen existir otros componentes que hay que valorar. Por ejemplo, es muy frecuente que el procedimiento se combine con técnicas operantes. Dispensar reforzadores aplicados al uso de las verbalizaciones ha permitido conseguir buenos resultados en niños impulsivos (Robertson, 1974; Bornstein, 1976; MacPherson et col., 1974). Pero no hay que olvidar que el uso involuntario y no programado de los reforzadores (especialmente los sociales) puede haber ocasionado un sesgo en la aplicación e interpretación de los datos del entrenamiento en AI. Generalmente han sido personas (terapeutas, profesores, etc.) los que han aplicado el procedimiento y el control de esta variable puede no haber sido adecuadamente valorado.

Sin embargo se han llevado a cabo algunos intentos para esclarecer su influencia. En algunos diseños en donde se han utilizado grupos con refuerzo social y se han comparado con otros con $\mathrm{AI}$, se ha podido evaluar el efecto diferencial de los distintos tipos de tratamiento. Recientemente, se han presentado dos trabajos de este tipo en donde no sólo se han comprobado los distintos efectos creados por ambos procedimientos, sino que han podido sacarse conclusiones válidas sobre ciertas estrategias metacognitivas. Uno de ellos fue el de Bugenthal et col. (1978) con niños hiperactivos de escuela elemental. Con ellos organizó dos grupos, uno de refuerzo social y otro de entrenamiento en autoinstrucciones. A corto término no había diferencias significativas entre ambos grupos, si bien el procedimiento en AI fue más eficaz en los niños que no recibían medicamentos para tratar su hiperactividad y en 
aquellos otros que tenían desarrollado un buen sentido del autocontrol personal. Pero, a largo plazo, las diferencias sí se hicieron más nítidas. Los sujetos del grupo de AI incrementaron la percepción del control personal sobre las tareas académicas, si bien los niños del grupo de refuerzo social presentaron un cambio conductual que se reflejó en las puntuaciones que los profesores daban en la escala de Connor. La conclusión de los autores, que mantuvieron un seguimiento de seis meses en los efectos del tratamiento, fue la de que lo mejor es combinar ambas estrategias, pero empezando por el refuerzo social y pasando después al procedimiento de autocontrol.

En otro trabajo se combinaron técnicas operantes y de AI en cada uno de los dos grupos que se formaron con niños de doce años (Kendall y Wilcox, 1980). El paquete de aplicación para ambos grupos incluía modelado, AI y costo de respuesta. Los dos grupos diferían en la forma de presentar las AI. En uno se daban AI concretas, relacionadas con la tareas y en el otro AI más generales y conceptuales, basadas en los procedimientos de solución de problemas. Si bien tras el tratamiento ambos grupos presentaron diferencias respecto al grupo de atención-placebo, en el seguimiento de un mes sólo el grupo «conceptual» mantuvo las mejorías sobre los otros dos grupos (medidos en la escala de Connor y en la escala de autocontrol de Kendall-Wilcox).

Estos dos ejemplos nos señalan la conveniencia de incorporar y controlar variables operantes a la hora de hacer más eficaz un procedimiento de entrenamiento en $\mathrm{AI}$.

Pero desde un punto de vista de aplicación, hay un problema interesante que es preciso comentar. Me refiero a saber cuál es el momento más adecuado para aplicar el refuerzo. Es el problema que se ha denominado como de «di-haz» o «haz-di». ¿Es mejor que el niño explique la tarea y después la haga, o resulta más conveniente que la realice y luego nos la explique? Por otro lado, ¿en qué momento será más útil aplicar el refuerzo?, ¿después de la realización?, ¿cuando haya correspondencia entre ambas? Este problema ha sido muy estudiado (ver la revisión de Meichenbau, 1977). La conclusión alcanzada es la de que el «di-haz» es mejor que su inverso, facilitando así la función reguladora de la acción que ofrece el lenguaje. En cuanto a la aplicación del refuerzo, debe hacerse contingente con la «correspondencia» entre lo que se dice y lo que se hace, con lo que aumentamos, por otro lado, la probabilidad de aparición de la conducta no verbal.

Otra variable muy importante y que siempre estará presente durante el entrenamiento es el estilo de atribución del sujeto. Algunos trabajos han intentado ponderar la forma con la que este factor puede interferir o ayudar a la implantación del procedimiento y a sus resultados. La aplicación de procedimientos operantes para modificar la conducta de niños hiperactivos dio ocasion para observar un efecto curioso: muchos niños reaccionaban mal a la aplicación de un incentivo material externo, incluso volviendo a tasas de conducta desajustada propias de la etapa de prerreforzamiento. Este efecto se ha intentado explicar en función de la atribución que el sujeto hace acerca de las causas de su fracaso o de su éxito. El sistema de creencias del individuo acerca de los factores que afectan a su conducta y que, naturalmente, son el producto de su propia historia de aprendizaje, pueden así interferir sustancialmente en los resultados esperados. Ya Kazdin (1973) pudo comprobar hace tiempo cómo la conducta de un grupo de niños respondía mejor a los reforzadores que ellos creian que estaban reci- 
biendo que a los que realmente se impartían. Una atribución es una creencia momentánea o sostenida, de carácter causal que potencialmente puede influir sobre el control de una conducta. Para analizar el impacto del estilo de atribución sobre modos particulares de tratamiento, Bugenthal, Whalen y Henker (1977), llevaron a efecto una serie de experimentos. Una de las conclusiones más interesantes que consiguieron con niños hiperactivos fue la de que aquellos niños que atribuían su mejoría al azar mejoraron más con un programa de refuerzo social, mientras que aquellos otros que la vinculaban a su propio esfuerzo, mejoraron más con un EAI. Hay que señalar, por otro lado, que estas conclusiones también son coherentes con lo que podríamos haber deducido si hubiésemos pensado en términos de «locus de control».

Una consecuencia de todo ello es la necesidad de perfeccionar la relación entre las atribuciones y las afirmaciones del EAI. Incluir el estilo de atribución del sujeto en sus autoverbalizaciones puede ayudarle a incrementar su nivel de autocontrol. Dweck (1975) intentó comprobar el efecto diferencial de controlar esa variable en un grupo de niños que experimentaban reacciones extremas ante el fracaso. El objetivo consistía en lograr una reatribución del fracaso en un grupo que obtenía éxitos y fracasos, frente a otro grupo que sólo conseguía éxitos. En el primer grupo, es decir en el de reeducación de atribución, el experimentador acompañaba cada fracaso con una afirmación de que el niño tendría que intentarlo «con más fuerza», de modo que le indicaba que la realización inadecuada era debida a un esfuerzo insuficiente. Al final encontró que, cuando al grupo de éxitos contingentes con la tarea se le señalaba un fracaso, aparecía a continuación un deterioro evidente en la ejecución, mientras que los niños del grupo de reatribución mantuvieron y mejoraron su realización después del fracaso.

\section{Las metacogniciones}

Introducción

Hasta aquí hemos estado señalando algunos aspectos prácticos que deben observarse a la hora de confeccionar un programa de intervención. También hemos indicado la necesidad de cuidar los aspectos operante y atributivo del entrenamiento. Pero esto no es todo. El objetivo final de un entrenamiento en AI es conseguir que el sujeto «internalice» las autoverbalizaciones y las convierta en estrategias comunes a la hora de cônducirse, sentir o pensar. Necesitamos por tanto que el individuo aprenda a responder del modo esperado en lugares distintos, ante distintas situaciones y a lo largo del mayor tiempo posible. Es decir, buscamos el asegurar un máximo gradiente de generalización a lo largo de esas tres dimensiones.

El problema de la generalización es el caballo de batalla de todos los procedimientos de intervención terapéutica, sea cual sea su metodología y su filosofía. La idea rectora en muchos terapeutas de conducta para adscribirse a procedimientos de intervención mixtos, es decir, cognitivo-conductuales, es precisamente esa. La idea estaba en la cabeza del Dr. Meichenbaum cuando empezó a diseñar sus procedimientos de AI; quería incorporar elementos nuevos que permitieran una mayor generalización de los efectos del tratamiento de las terapias de conducta tradicionales. Pero los problemas teóricos y prácticos que surgen son 
difíciles. Hasta ahora nos hemos movido dentro de parámetros de acción manifiestos. Había modelos y tareas que se podían ver, verbalizaciones que se podían oír y ejecuciones que se podían contrastar; todo ello dentro de un contexto, con unos individuos y ante una tarea determinados. Ahora, buscando la generalización, necesitamos saber qué dirección tomar. En principio parecen surgir dos orientaciones que pueden resultar complementarias. Las teorías del aprendizaje de la conducta manifiesta nos podrían señalar que un diseño ambiental determinado podría facilitar el mantenimiento y la generalización de las respuestas deseadas. Pero, en la práctica, las limitaciones de esta alternativa son obvias. Un diseño cultural y ambiental ad hoc sólo es posible para áreas restringidas de población y disponiendo de medios que en general están fuera de nuestro alcance. Por otro lado, los problemas teóricos no son nada despreciables (ver, por ejemplo, Fernández Ballesteros, 1983).

La otra alternativa es volver hacia «dentro», hacia la «caja negra» y ver si se puede «trabajar con ella». Pero debemos tener presente de ahora en adelante que ya no nos vamos a referir a sucesos públicos, como hemos hecho hasta ahora. Nuestro primer objetivo no va a ser inducir un cambio manifiesto por imitación o modelado (ni siquiera utilizando inferencias de primer orden). Ahora, y antes de eso, vamos a intentar cambiar «el pensamiento», las «estructuras cognitivas y metacognitivas» y cosas de ese estilo para, a través de ello, conseguir una mayor generalización de las respuestas manifiestas. Hemos buscado un rodeo quizá motivados por tres tipos de influencias. La vía conductual pura parece inviable por rozar la pura utopía. Otra influencia viene de nuestra tradición cultural y, paradójicamente, la tercera influencia se refiere a una creencia en la accesibilidad de los datos contenidos en la «caja negra». Y digo «paradójicamente» porque una de las razones que movieron a Skinner y a orros a «no meterse ahí» fue la falta de accesibilidad de los datos subjetivos, así como la indefinición del objeto de estudio. Pero ahora hemos cambiado de idea. Hemos construido un nuevo lenguaje y esto nos hace pensar que también pisamos una nueva tierra. Pero también he hablado de la influencia de la tradición cultural, $y$, al decir esto, me estoy refiriendo más concretamente a la creencia que sostiene el carácter causal de nuestros pensamientos para dirigir nuestra conducta. La cultura mantiene «patrones de atribución» que con demasiada frecuencia nunca han sido verificados. Uno de ellos es éste. Nosotros nos conducimos «según pensamos», «según creemos», y estos «fantasmas» se mantienen tan firmemente que finalmente no hemos tenido más remedio que hacerles caso. Adentrémonos en el castillo a ver qué tipo de personajes nos encontramos.

\section{Justificación}

Como ya señaló Vygotsky (1962), el proceso de internalización del lenguaje para transformarse en pensamiento no es un mero fenómeno de debilitamiento del habla. Implica cambios estructurales de carácter cualitativo. No podemos, por tanto, afirmar que el uso instrumental del lenguaje por parte de un niño en la ejecución de una tarea entrañe un cambio automático en su modo de pensar. Aún más, las pruebas a favor de la existencia de un desarrollo cognitivo por fases o etapas representa otro obstáculo adicional a tener en cuenta. De hecho, algunos 
investigadores de orientación piagetiana han señalado que haciendo que los niños se hablen a sí mismos de cierta forma, se les ayuda a dirigir su atención y a controlar sus actividades perceptuales, pero no da como resultado nuevas operaciones cognitivas, operaciones que más bien surgen con el desarrollo de estructuras como, por ejemplo, las que se ilustran en los experimentos de conservación (Sinclair de Zwart, 1969; Inhelder, Sinclair y Bovet, 1974). De algunos experimentos se deduce que el entrenamiento lingüístico en frases o palabras tales como «más que», «mayor que», "tanto como», etc., en niños que no habían alcanzado la noción de conservación, no daba lugar a una mejora en tareas de conservación. Si bien estas conclusiones han sido en parte contestadas por Meichenbaum (1977), puede sugerirnos que para las A1 puedan tener alguna utilidad no sólo resulta preciso poseer habilidades previas que están en la base de la ejecución o de la comprensión del individuo, sino que si aceptamos la existencia de etapas estructurales en el desarrollo cognitivo, las posibilidades en el EAI estarían limitadas por el nivel evolutivo en el que se encontrase el sujeto. De hecho el trabajo de Schleser, Meyers y Cohen (1978) confirma de algún modo este punto de vista.

En definitiva, y aunque no conozcamos con la precisión necesaria el modo con el que las autoverbalizaciones se convierten en pensamientos, Meichenbaum en distintas ocasiones ha reiterado el fundamento de su esperanza sobre la efectividad del EAI. Apoyándose precisamente en un seguidor de Piaget (Furth, 1966), cree que, si bien el pensamiento puede ocurrir sin lenguaje, el lenguaje puede mejorar de manera notable el pensamiento, y, por tanto, afectar a la conducta. Esta es la premisa del enfoque del entrenamiento cognitivo-conductual en autoinstrucciones (Meichenbaum, 1977). Siguiendo el hilo argumental, la pregunta obligada que podríamos plantearnos debería ser del siguiente estilo: ¿cómo podemos mejorar eso que ha dado en llamarse «diálogo interno» (siguiendo a Platón) o «automanifestaciones» o de otros muchos modos?, ¿qué se dice la gente a sí misma cuando va a iniciar una tarea difícil, durante el tiempo en que la ejecuta y después de finalizarla?, ¿podríamos encontrar reglas o metarreglas que facilitasen la labor? A las metacogniciones se las ha definido como el «conocimento acerca del conocimiento» (Brown, 1977). Es decir, el conocimiento del sujeto acerca de su propia organización cognitiva y de la forma en la que ésta opera. Para Meichenbaum, y a efecto de los objetivos de la CBM, las metacogniciones de interés serían aquellas automanifestaciones que un sujeto se dice a sí mismo antes, durante y después de llevar a cabo una tarea (Meichenbaum y Genest, 1980). Si esto pudiese alterarse positivamente, no sólo podríamos conseguir modificar el pensamiento del sujeto, sino que, a través de esta modificación, deberíamos esperar una mayor generalización de los efectos del tratamiento. $\mathrm{Y}$ es en esta dirección, más que en estudiar cómo se altera el pensamiento, hacia donde se han dirigido los mayores esfuerzos de investigación. Hemos anotado previamente que la generalización era el caballo de batalla de las intervenciones terapéuticas. Hemos señalado también las limitaciones de la pura planificación conductual. Tras un largo recorrido (Meichenbaum inició sus investigaciones en 1969, si mis datos son correctos), nuestras ilusiones se centran ahora en el conocimiento del desarrollo metacognitivo. ¿Qué nos puede ofrecer esa nueva «aparición»? 


\section{Trabajos iniciales}

Los trabajos sobre este campo se iniciaron centrándose en el estudio de la memoria (Flavell y Wellman, 1977) y sucesivamente se han ido extendiendo a otras áreas. Algunos ejemplos pueden ser la atención (Miller y Bigi, 1976), la comprensión de la lectura (Meyers y Paris, 1978), el autocontrol (Mischel, Mischel y Hood, 1978), la comunicación (Markman, en prensa), etc. Un ejemplo que nos puede ilustrar el concepto de metamemoria sería el caso de un niño de jardín de infancia que sabe que una tarea de memoria es más difícil si tiene un gran número de items, mientras que sólo unos niños mayores que éstos saben que recordar una tarea es más difícil si se tienen que aprender dos series de palabras que puedan confundirse fácilmente (Krentzer, Leonard y Flavell, 1975).

\section{El concepto de «estrategia cognitiva»}

Un concepto recurrente en el ámbito de las metacogniciones es el de estrategia cognitiva. Su correlato en el ámbito de la conducta observable es evidente. Las habilidades que demuestra un artesano para modelar con finos movimientos de sus manos y sus pies una figura de arcilla, tienen su equivalente subjetivo en lo que denominamos «estrategias cognitivas». El término y su significado son viejos en la historia de la Psicología. Pero la acepción más utilizada en el círculo de los seguidores de la CBM es la que utilizaron Gagné y Briggs (1974):

«Una estrategia cognitiva es una habilidad organizada internamente que selecciona y dirige los procesos internos implicados en la definición y en la solución de nuevos problemas. En otras palabras, es una habilidad por medio de la cual la persona que está aprendiendo maneja su propia conducta de pensar...». En el ámbito del entrenamiento en AI se trataría de enseñar a «cómo» pensar más que a «qué» pensar. $\mathrm{El}$ aprendizaje de estrategias cognitivas permite guiar y regular el pensamiento al modo en que lo hacen las paredes de un sinuoso pasillo para los pasos del caminante, aunque con una sustancial diferencia: nosotros podríamos modificar el trazado de las paredes según la estrategia elegida y los requerimientos de la tarea. El objetivo de la estrategia son los propios pensamientos, pero en relación con la tarea.

\section{Generalización y estrategia cognitiva}

A fin de facilitar la generalización y la eficacia en las intervenciones de CBM se hace, por tanto, preciso incorporar en el programa un entrenamiento en estrategias. Ya Miller et al. (1960) decían que el fallo general del niño era el «no ser estratégico». O como más recientemente se ha dicho: «el fallo consiste en no tener un plan para formar un plan» (Campione y Brown, 1978). Como indicaban Baer, Wolf y Risley (1968), «la generalización debería ser programada, mejor que esperada o lamentada», y un componente importante en esta programación sería enseñar estrategias generales. Meichenbaum y Genest (1980) apuntan que dos pasos fundamentales en ese entrenamiento serían: 1. ${ }^{\circ}$ ) Aprender a detectar problemas y $2 .{ }^{\circ}$ ) Aprender a formular soluciones alternativas.

Pero de un modo más extenso, tres grupos de investigadores han descrito los requerimientos para la generalización de las instrucciones: Borkowski y Cavanaugh (1978), Campione y Brown (1977) y Belmont 
y Butterfield (1977). Veamos las recomendaciones de Borkowski y Cavanaugh (1978):

\begin{abstract}
«Primero, necesitamos identificar diversas estrategias, que sean operativas en diferentes situaciones de aprendizaje. Segundo, necesitamos entrenar a los niños en diferentes estrategias, asegurándonos de que saben cuándo y cómo aplicarlas. Tercero, conviene entrenarles en un paquete de instrucciones de forma que se evidencien los elementos comunes existentes entre el contexto de entrenamiento y el contexto de generalización, de manera que sean mínimos los aspectos que puedan distraer a los niños. Cuarto, necesitamos desarrollar rutinas de búsqueda autogeneradas, probablemente utilizando procedimientos de autoinstrucción, que animan al niño a analizar una tarea, a explorar su repertorio estratégico y a emparejar las exigencias de la tarea con una estrategia apropiada y un plan de recuperación. Quinto, instruir al niño de tal manera que utilicemos cualquier habilidad que tenga, a fin de llevarle al conocimiento de las ventajas que presenta un control sobre la ejecución y el tomar decisiones a la hora de resolver problemas. Finalmente, conviene reforzar de un modo explícito las realizaciones que han tenicio éxito, a fin de ponerlas bajo el control de contingencias ambientales naturales, tales como los sentimientos adecuados que experimenta un niño tras la solución de un problema difícil» (pág. 54) ${ }^{1}$.
\end{abstract}

El uso de las metacogniciones en el EAI ha llevado a Meichenbaum y Cameron (1980) a recomendar el uso de tres pasos en relación con el contenido de las AI. Serían éstos:

1. Dar una oportunidad al niño para que realice la tarea.

2. Pasar al uso de AI concretas.

3. Introducir AI de carácter abstracto.

\title{
Resumen del procedimiento en un EAI
}

Todas las observaciones prácticas apuntadas al principio del escrito pueden ser resumidas tal y como lo ha hecho Meichenbaum en diversas ocasiones (Meichenbaum, 1977; Mechenbaum y Cameron, 1980). Este paquete, unido a las recomendaciones de Borkowski y Cavanaugh (1978) acerca de la generalización de las AI, nos ofrece, según los autores, un esquema valioso a la hora de planificar y llevar a cabo un EAI. Las diez sugerencias de Meichenbaun (Meichenbaum y Cameron, 1980) son las siguientes:

1. Usar el juego como un medio propio del niño para iniciar y modelar «el hablarse a sí mismo».

2. Usar tareas ricas de las que puedan extraerse estrategias cognitivas de forma secuenciada.

3. Entrenar a un compañero de clase para que actúe como modelo de los otros niños.

4. Hacer que el niño lleve a cabo el programa a su propio ritmo, mientras va confeccionando el paquete de AI que deberá incluir una variedad de soluciones al problema así como elementos de autorrefuerzo y enfrentamiento.

5. Estar atentos a que el niño no use las AI de una forma mecánica, sin implicarse en su comprensión y sin afectividad. 
6. Incluir un terapeuta que sea animado y con capacidad de respuesta ante el niño.

7. Enseñar el uso del entrenamiento en autoinstrucciones con respuestas de baja intensidad.

8. Suplementar el entrenamiento con la práctica de imágenes, tales como la «técnica de la tortuga» (Schneider y Robin, 1975).

9. Complementar este procedimiento con el entrenamiento de correspondencia entre el decir y el hacer (Rogers, Warren y Baer, 1976).

10. Introducir procedimientos operantes tales como un programa de coste de respuesta (Kendall y Finch, 1976, 1978; Nelson y Birkimer, 1978; Robertson y Keeley, 1974). (pág. 403).

\section{Evaluación de los resultados y análisis critico}

El diseño más utilizado para investigar sobre las AI en niños ha consistido en la comparación de tres grupos (Meichenbaum, 1979): un grupo de entrenamiento en autoinstrucciones, otro grupo de práctica o placebo que se somete a las mismas tareas que los otros grupos y tiene el mismo contacto con el experimentador, pero no recibe EAI, y un grupo de control del que sólo se obtienen evaluaciones pre-post.

«Los resultados obtenidos apuntan hacia la conclusión de que el grupo de EAI obtiene mejores resultados según algunos índices psicométricos (sólo en algunos, no se da en todos), pero ese resultado no se generaliza al aula tal y como se ha evaluado normalmente según la escala de clasificación de los profesores de Connors» (Meichenbaum, 1979, pág. 2).

Pero antes de continuar es preciso señalar que el procedimiento de las AI casi nunca se ha empleado solo, de manera que su validez como conjunto aislado resulta poco conocida. En este sentido quizá resulte más apropiado hablar de programas de entrenamiento cognitivo-conductuales que, junto con otros elementos, incluía un tipo de entrenamiento en AI. Estos programas de conjunto han sido evaluados en distintas ocasiones (Meichenbaum, 1979; Meichenbaum y Cameron, 1980; Meichenbaum y Asarnow, 1979; Lahey, Delamater y Kupfer, 1981, etc.) y algunos de ellos han sido comentados anteriormente. En relación con la generalización de las habilidades adquiridas a otras situaciones y momentos (no debemos condundir generalización con mantenimiento), la revisión de Meichenbaum y Asarnow (1979) establece tres categorías de resultados: los ambiguos, los notables y los de eficacia relativa. Entre los primeros se citan siete investigaciones, entre los notables dos (una de ellas es el de Douglas -1976-, que empleó un total de 44 sesiones de una hora, incluyendo el entrenamiento de padres y maestros para favorecer la generalización), y para los de eficacia relativa, otras dos. La conclusión final de la eficacia en la generalización de los conjuntos de CBM en niños es la de que resulta ambigua. Meichenbaum y Cameron (1980) se apresuran a recordarnos que «una serie de conclusiones similares se podrían extraer de otras aproximaciones al cambio de conducta, tales como el condicionamiento operante» (pág. 396). Pero esta observación de Meichenbaum no nos consuela lo más mínimo, sobre todo si recordamos que uno de los motivos más importantes por los que hizo más «complejos» y «cognitivos» los procedimientos de terapia de conducta, al iniciar sus investigaciones allá por 
1969, fue el de aumentar la generalización de sus resultados. Al parecer la intervención de variables cognitivas no ha permitido ampliar claramente nuestras expectativas sobre este importante tema. Nosotros podríamos añadir algunos breves comentarios críticos acerca de este procedimiento.

1. Uno de carácter general y que afecta tanto a los procedimientos de AI como a los de la CBM, consistiría en repetir las críticas al viejo concepto de «estrategia cognitiva» (ver Wiest, 1967; Rachman y Eysenck, 1966; Bas, 1981). Una «estrategia cognitiva» no explica científicamente nada. Lo que sí puede explicar son las conductas verbales que el sujeto aprende en forma de reglas o metacogniciones. Estos son los datos objetivos que poseemos y una explicación científica debería soportarse en ellos y no en inferencias (¿de qué orden?). Otra cosa es la utilidad que nos pue$\mathrm{da}$ aportar un nuevo concepto. $\mathrm{Si}$, por ejemplo, nos ayudase a predecir la conducta con más exactitud, podría servirnos para continuar caminando, aun cuando no supiéramos muy bien de lo que estábamos hablando.

2. La mayoría de las intervenciones del EAI que ofrece la literatura incluyen pocas sesiones de tratamiento. El número de sesiones en cualquier intervención es una variable relevante y no conocemos los criterios que se han utilizado para elegir un número de sesiones tan bajo.

3. Los seguimientos de estos trabajos son en general muy cortos, y no podemos esperar la credibilidad precisa si no disponemos de seguimientos razonablemente largos.

4. La influencia relativa de los distintos componentes del entrenamiento no ha podido evaluarse por separado. Como ya apuntamos en otro lugar (Bas, 1981) al referirnos a las aplicaciones de técnicas derivadas de los procedimientos de autoinstrucción («inoculación de estrés»), el modelado cognitivo, las imágenes, los estímulos instigadores, el aprendizaje vicario y los efectos de refuerzo no programados pueden jugar un importante papel en los resultados finales, sin que podamos conocer el peso relativo de cada componente.

5. Los procedimientos sugeridos para favorecer la generalización no se han basado en el estudio empírico y funcional de los errores en el autocontrol, sino en supuestos teóricos que en gran medida pueden haber tenido su origen en los modelos del procesamiento de la información o en apreciaciones conceptuales sobre el funcionamiento hipotético de las estructuras cognitivas.

6. En un plano estrictamente cognitivo, parece un requisito necesario que el contenido de las AI resulte «creíble» para el niño. Esta variable sólo se contempla indirectamente en el entrenamiento pero su importancia puede ser fundamental (ver Bas, 1982).

7. Acerca de los resultados sobre la generalización, éstos no parecen distinguirse de los que han podido conseguirse con las técnicas de autocontrol en general. Una revisión reciente sobre los fallos en el autocontrol en relación a la generalización efectuada por Kirschenbaum y Tomarken (1982) señala que el estudio de los dos procedimientos más ampliamente usados, es decir, las se- 
siones «booster» y el entrenamiento en autorregulación «presentan limitaciones sustanciales en su efectividad» (pág. 177).

De cualquier modo, y al margen de las limitaciones generales y particulares que pueda presentar el método, el hecho de que haya podido funcionar en determinadas ocasiones y de que su aplicación no se haya realizado normalmente con la intensidad o extensión necesarias, nos debe invitar a proseguir en las investigaciones con actitud esperanzadora.

\section{Referencias}

Abramson, L. Y.; Seligman, M. E. P., y Teasdale, J. D. «Learned Helplessness in Humans: Critique and Reformulation». Journal of Abnormal Psycbology, 1978, 87, 1, 49-74.

BAER, D.; WOLF, M. y RISLEY, T. «Some current dimensions of applied behavior analysis». Journal of $A p$ plied Behavior Analysis, 1968, 1, 91.97.

Bas Ramallo, F. «Las terapias cognitivo-conductuales: una revisión». Estudios de Psicología, 1981, 7, 92-114.

Bas Ramallo, F. La transferencia de la autocredibilidad: un ensayo experimental. Memoria de Licenciatura. Universidad Autónoma de Madrid, 1982.

BECK, A. T. «Thinking and depression: 1. Idiosyncratic content and cognitive distortions». Archives of General Psychiatry, 1963, 9, 324-333.

BECK, A. T. «Thinking and depression: 2. Theory and Therapy». Archives of General Psychiatry, 1964, 10, $561-571$.

BECK, A. T. Depression: Causes and Treatment. Philadelphia: University of Pennsylvania Press, 1967

BECK, A. T. Cognitive therapy and the emotional disorders. Nueva York: International Universities Press, 1976.

BECK, A. T. y SHAw, B. F. «Enfoques cognitivos de la depresión», en A. Ellis y R. Grieger: Manual de Terapia Racional-Emotiva. Bilbao, Desclee de Brouwer, 1981.

BeCK; A. T.; NARD, C. H.; Mendelson, M.; MoCK, J. E., y ERbaugh, J. K. «A inventary for measuring depression». Archives of General Psychiatry, 1961, 4, 561-571.

BELMONT, J., y BUTTERFIELD, E. «The instructional approach to developmental cognitive research», en R. Kail y J. Hagen (Eds.): Perspectives on the development of memory and cognition. Hillsdale, N. J.: Lawrence Eulbaum, 1977.

BEM, S. "Verbal self-control: The establishment of effective self-instruction». Journal of Experimental Psychology, 1967, 74, 485-491.

BENDER, N. N. «Self-verbalization versus strategy training: The inmediate effects of verbal self-instruction training on impulsive first grade children». Escrito presentado a la American Education Research Association, Washington, D. C., abril de 1975.

BORKOWSKI, J., y CAVANAUGH, J. «Maintenance and generalization of skills and strategies by the retarded», en N. ElLIS (Ed.): Handbook of mental deficiency: Psychological theory and research. Segunda edición. Hillsdale, New Jersey: Lawrence Erlbaum, 1978.

BORNSTEIN, P., y QUEVILLON, R. «The effects of a self-instructional package on overactive preschool boys». Journal of Applied Behavior Analysis, 1976, 9, 179-188.

BROWN, A. «Development, Schooling and the acquisition of knowledge about knowledge» en R. ANDERSON, R. SPIRO y W. MONTAGUE (Eds.): Schooling and the acquisition of knowledge. Hillsdale, N. J.: Erlbaum, 1977.

Bugenthal, D. B.; Collins, S.; Collins, L., y Chaney, L. «Attributional and behavioral changes following two behavior management interventions with hiperactive boys: $A$ follow-up study». Child $D e$ velopment, 1978, 49, 247-250.

Bugenthal, D.; WhALEN, C., y HeNKER, B. "Causal attributions of hyperactive children and motivational assumptions of two behavior-change approaches: Evidence for an interactionist position». Child Development, 1977, 48, 874-884.

CACIOPPO, J. T.; Glass, C. R., y MERLuZZI, T.V. «Self-statements are self-evaluations: A cognitive response analysis of heterosexual sorial anxiety». Cognitive Therapy and Research, 1979, 3, 249-262.

CAMP, B. «Verbal mediation in young aggressive boys». Journal of Abnormal Psychology, 1977, 86, 145-153.

Camp, B.; Blom, G.; HerberT, F., y Van DooRwick, W. Think aloud: A program for developing selfcontrol in young agressive boys. Texto inédito. University of Colorado School of Medicine, 1976. Journal of Educational PsycBorogy, 1977, 69, 129-135. 
CAMPIONE, J., y BROWN, A. «Memory and metamemory development in educable retarded children», en R. Kail y J. Hagen (Eds.): Perspectives on the development of memory and cognition. Hillsdale, $\mathbf{N}$. J.: Lawrence Erlbaum, 1977.

CAMPIONE, J. C., y BROWN, A. L. Toward a theory of intelligence: Contributions from research with retarded children. Trabajo presentado en la American Educational Research Association, Toronto, 1978.

COPELAND, A. P. «Types of privates speech produced by hyperactive and nonhyperactive boys». Journal of Abnormal Child Psychology, 1979, 7, 169-177.

COPELAND, A. P. «The relevance of subject variables in cognitive self-instructional programs for impulsive children». Bebavior Therapy, 1981, 12, 520-529.

Copeland, A. P., y Hammel, R. «Subject variables in cognitive Self-Instructional Training». Cognitive Therapy and Research, 1981, 4, 405-420.

Covington, M. V. y OMeliCH, C. L. «Are Causal Attributions Causal? A path analysis of the cognitive model of achievement motivation». Journal of Personality and Clinical Psychology, 1979, vol. 37, n. 9 9, 1487-1504.

Craighead, W. E.; Kimball, W. H., y Rehak, P.J. «Mood changes, physiological responses, and Selfstatements during sorial rejection imagery». Journal of Consulting and Clinical Psychology, 1979, 47, 385-396.

Davison, G. C.; Robin, C., y Johnson, M.K. «Articulated Thoughts During Paradigm for Studying Cognition in Emotion and Behavior». Cognitive Therapy and Research, 1983, 7, n. ${ }^{\circ} 1,17-39$.

DENNEY, D. R. «The effects of exemplary and cognitive models and self-rehearsal on children's interrogative strategies». Journal of Experimental Child Psychology, 1975, 19, 476-488.

DICKIE, J. Private speech: The effect of presence of others, task and intrapersonal variables. Tesis doctoral inédita. Michigan State University, 1973.

DOUGLAS, V. «Stop, book and listen: The problem of sustained attention and impulsive control in hyperactive and normal children». Canadian Journal of Behavioral Science, 1972, 4, 259-276.

Douglas, V.; Parry, P.; MARTon, P., y GARSON, C. «Assessment of a cognitive training program for hyperactive children». Journal of Abnormal Child Psychology, 1976, 4, 389-410.

DWECK, $C$. «The role of expectations and attributions in the alleviation of learned helplessness». Journal of Personality and Social Psychology, 1975, 31, 674-685.

EluIs, A. Reason and emotion in psychotherapy. Nueva York: Lyle Stuart Press, 1962.

ElLIS, A. «Rational-emotive therapy: Research data that support the clinical and personality hypotheses of RET and other modes of cognitive-behavior therapy». The Counseling Psychologist, 1977, 7 (1), $2-42$.

EluIs, A. «A Reappraisal of Rational-Emotive Therapy's Theoretical Foundations and Therapeutic Methods: A Replay to Eschenroeder». Cognitive Therapy and Research, 1982, 6, 393-398.

ELLIS, A., y GRIEGER, R. Rational-Emotive Therapy: A bandbook of theory and practice. Nueva York: Springer, 1977.

ERICsson, K. A. y Simon, H. A. «Verbal reports as data», Psychological Review, 1980, 87, 215-251.

ESChENROEDER, $\mathrm{CH}$. «How Rational Is Rational-Emotive Therapy? A critical Appraisal of Its Theoretical Foundations and Therapeutic Methods». Cognitive therapy and Research, 1982, 6, 381-391.

EYSENCK, $\mathrm{H}$. The dynamics of anxiety and hysteria. Londres: Roucledge and Kegan Paul, 1957.

FERNÁNDEZ BALLESTEROS, R. «Contenidos y modelos en evaluación conductual, en R. Fernández Ballesteros y J. A. I. Carrobles (Eds.): Evaluación conductual. Metodología y aplicaciones. Madrid, Pirámide, 1981.

FERNANDEz Ballesteros, R. «El contexto en evaluación psicológica», en R. Fernández Ballesteros: Evaluación de contextos. 1. ${ }^{a}$ Reunión Nacional sobre Intervención Psicológica, Universidad de Murcia, 1983.

FernÁNDEz Ballesteros, R., y Manning, L. «Evaluación de conductas cognitivas, en R. Fernández Ballesteros: Psicodiagnóstico. Vol. 2. Madrid: UNED, 1983.

FinCH, A.; WILKINSON, M.; NeLSON, W., y MONTGOMERY, L. «Modification of an impulsive cognitive tempo in emotionally disturbed boys». Journal of Abnormal Child Psychology, 1975, 3, 45-52.

Flavell, J., y Wellman, H. «Metamemory. En R. Kail Y J. Hagen (Eds.): Perspectives on the development of memory and cognition. Hillsdale, N. J.: Lawrence Erlbaum, 1977.

FURTH, H. Thinking without language. Nueva York: The Free Press, 1966.

GAGNE, R., y BRIGGS, L. Principles of instructional design. Nueva York: Holt, Rinehart y Winston, 1974.

GALPERIN, P. «Stages in the development of mental acts, en M. Cole y I. Maltzman (Eds.): $A$ bandbook of contemporary Soviet Psychology. Nueva York: Basic Books, 1969.

Glass, C. R., MerLuZzi, T. V., BIEVER, J. L. y LARSEN, K. H. «Cognitive assessment of sorial anxiety: Development and validation of a self-statement questionnaire». Cognitive Therapy and Research, $1982,6,37-55$.

GOOR, R., y SOMMERFELD, R. «A comparison of problem-solving processes of creative students and noncreative students». Journal of Educational Psychology, 1975, 67, 495-505.

GotTMAn, J.; Gonson, J., y RASMUSSEN, B. Sorial interaction, social competence and friendship in children. Texto inédito. Indiana University, 1974.

Gruson, L. Piano practicing skillsl: What distinguishes competence? Tesis doctoral inédita. University of Waterloo, 1980. 
HARTING, M., y KANFER, F. «The role of verbal self-instructions in children's resistance to temptation». Journal of Personality and Sorial Psychology, 1973, 25, 259-267.

HENSHAW, D. Cognitive mediators in creative problem solving. Tesis doctoral inédita. University of $\mathrm{Wa}_{\mathrm{a}}$ terloo, 1977.

Hollon, S. D., y KENDALl, P. C. «Cognitive self-statements in depression: Development of an automatic thoughts questionnaire». Cognitive Therapy and Research, 1980, 4, 109-143.

HURLBURT, R. T. «Ramdon sampling of cognitions and behavior». Journal of Research in Personality, $1979,13,103-111$.

INHELDER, B.; SINCLAIR, H., y BOVET, M. Learning and the development of cognition. Cambridge, Mass.: Harvard University Press, 1974.

JABICHUK, Z., y SMERIGLIO, V. "The influence of symbolic modeling on the social behavior of preschool children with low levels of sorial responsiveness». Child Development, 1976, 47, 838-841.

JENSEN, A. "Verbal mediation and educational potential». Psychology in the Schools, 1966, 3, 99-109.

KANFER, F. H. «Self-Regulation: Research issnes and speculations», en C. Neuringer y J. L. Michael (Eds.): Behavior Modification in Clinical Psychology. Nueva York: Appleton-Century-Crofts, 1970.

KANFER, F. H. «The maintenance of behavior by self-generated stimuli and reinforcement, en A. Jacobb y L. B. Sachs (Eds.): The psychology of private events: Perspectives on covest response systems. Nueva York: Academic Press, 1971.

KANFER, F.H. y KAROLY, P.: Self-Control: A behavioristic excursion into the lion's deu. Behavior Therapy, 1972, 2, 398-416.

KANFER, F. H., y KAROLY, P. y NeWMAN, A. «Reduction of children's fear of the dark by competence velated and situational threat related verbal cues». Journal of Consulting and Clinical Psychology, $1975,43,251-258$.

KaRnES, M.; TeSKA, J., y Hodgins, A. «The effects of fonu programs of classroom intervention on the intellectual an language development of 4-year-old disadvadvantaged children». American Joumal of Orthopsychiatry, 1970, 40, 58-76.

KAZDIN, A. E. «The failure of some patients to respond to token programs». Bebavior Therapy and Experimental Psychiatry, 1973, 4, 7-14.

Kendall, P. C., y BRASNell, L. On cognitive behavioral assessment: model measures and madness, en C. D. Spielberger y S. N. Butche (Eds.): Advances in personality assessment. Hillsdale N. J.: L. E. A., 1982.

Kendali, P. C., y FinCH, A. J. «A cognitive-behavioral treatment for impulse control: A case study». Journal of Consulting and Clinical Psychology, 1976, 44, 852-857.

Kendall, P. C., y FINCH, A. J. «A cognitive-behavioral treatment for impulsivity: A group comparison study». Journal of Consulting and Clinical Psychology, 1978, 46, 110-118.

Kendall, P. C., y Hollon, S. D. (Eds.), Assessment strategies for cognitive behavioral intervention. New York, Academic Press, 1981.

Kendall, P. C., y KogersKI, G. P. «Assessment and cognitive-behavioral interventions». Cognitive Therapy and Research, 1979, 3, 1-21.

KENDALL, P., y WILCOX, L. «A cognitive-behavioral treatment for impulsivity: Concrete versus conceptual lobeling with nonself-controlled problem children». Journal of Consulting and Clinical Psychology, $1980,48,80-91$.

Kendall, P. C.; Williams, L.; Pechacek, T. F.; Graham, L. E.; Shisslak, C., y Herzof, N. «Cognitivebehavioral and patient education interventions in cardiac catheterization procedures: The Palo Alto medical Psychology project». Journal of Consulting and Clinical Psychology, 1979, 47, 48-59.

Kirschenbaum, D. S., y Tomarken, A. J. «On facing the Generalization Problem: The Study of Self-Regulatory Failure, en P. C. Kendall (Ed.): Advances in Cognitive-Behavioral Research and Therapy, Vol. 1. Nueva York, Academic Press, 1982.

KEIN, W. An investigation of the spontaneus speech of children. Tesis doctoral inédita. University of Rochester, 1963.

KLINGER, E. Thought content, anxiety, and essay test performance. Texto inédito. University of Minnesota, 1978.

Kohlberg, L.; Yaeger, J., y HJertholim, E. «Private Speech: Four studes and a review of theories». Child Development, 1968, 39, 691-736.

KREUTZER, M.; LEONARD C., y FLAVELL, J. «An interview study of children's knowledge about memory». Monographs of the Society for Research in Child Development, 1975, 40 (1 Serial, $\mathrm{n} .{ }^{2}$ 159).

LA PoINTE, K. A., y HARrell, T. H. «Thoughts and feelings: Correlational relationships and cross-situational consistency". Cognitive Therapy and Research, 1978, 2, 311-322.

LAMEY, B. B.; DelAMATER, A., y KUPFER, D.: Intervent on Strategies with Hyperactive and Learning-Disabled Children, en S. M. Turner, K. S. Calhoun y H. E. Adams: Handbook of Clinical Bebavior Therapy. John Wiley Sons., Nueva York, 1981.

LANDAU, R. J., y GoldFRIED, M. R. «The assessment of schemata: A unifing framework for cognitive behavioral, and traditional assessment». En P. C. Kendall y S. D. Hollon (Eds.): Assessment Strategies for Cognitive Behavioral Interventions. Nueva York: Academic Press, 1981.

Lieberman, D. A. «Behaviorism and the mind: A (limited) call for a return to introspection». American Psycholigist, 1979, 34, 319-333. 
LUNDH, L. G. «Introspection conciusness and human information and human information-procesing». Scandinavian Journal of Psychology, 1979, Vol. 20, 223-238.

LuRIA, A. «The directive function of Speech in development». Word, 1959, 18, 341-352.

LURIA, A. "The role of Speech in the regulation of normal and abnormal behaviors. Nueva York: Livelright, 1961.

Mac Pherson, E.; CANDEe, B., y Hohman, R. «A comparison of three methods for elementary disruptive lunchroom behavior». Journal of Applied Behavior Analysis, 1974, 7, 287-297.

MAHONEY, M. J., y AVENER, M. «Psychology of the elite athlete: An exploratory study». Cognitive Therapy and Research, 1977, 1, 135-141.

McMulLIN, R., y CASEY, W. Talk sense to yourself. Lakewood, Colorado: Counseling Research Institute, 1975.

McMulin, R., y GiLes, T. R. Cognitive-behavior Therapy. A restructuring approach. Grune y Stratton, Nueva York, 1981.

MEICHENBAUM, D. "The effects of instructions and reinforcement on thinking and language behaviors of schizophrenics》. Bebaviors Research and Therapy, 1969, 7, 101-114.

MEICHENBAUM, D. The nature and modification of impulsive children. Escrito presentado en la reunión de la Sociedad para la Investigación del Desarrollo Infantil. Minneapolis, 1971.

MeICHEnBaum, D. Therapist manual for cognitive behavior modification. Texto inédito. University of Waterloo, 1973.

Meichendaum, D. «Self-instructional training: A cognitive prosthesis for the aged». Human Development, 1974, 17, 273-280.

MeICHENBAUM, D. «Theoretical and treatment implications of development research on verbal control of behavior». Canadian Psychological Review, 1975, 16, 22-27.

Meichenbaum, D. Cognitive behavior modification. Nueva York: Plenum Press, 1977.

MeicheNBAUM, D. Cognitive Bebavior Modification. Newsletter. University of Waterloo, 1979.

Meichendaum, D. «Cognitive Behavior Modification: The need for a faire assessment». Cognitive Therapy and Research, 1979, 3, 127-130.

Meichenbaum, D., y Asarnow, J. «Cognitive-Behavioral Modification and Metacognitive Development: Implications for the Classroom, en P. C. Kendall y S. D. Hollon (Eds.): Cognitive-Bebavioral Interventions: Theory, Research and Procedures, Academic Press: Nueva York, 1979.

Meichenbaum, D., y Catieron, R. «Cognitive behavior modification. En C. Franks y T. Wilson (Eds.): Handbook of Behavior Therapy. Nueva York, Quilford Press, 1980.

Meichenbaum, D., y GenesT, M. «Cognitive behavioral modification: An integration of cognitive and behavioral methods, en F. Kanfer y A. Goldstein (Eds.): Helping people change. Nueva York: Pergamon, 1980.

Meichendaum, D., y Goodman, J. «Reflection-impulsivity and verbal control of motor behavior». Child Development, 1969, 40, 785-797.

Meichendaum, E., y Goodman, J. «Traiining impulsive children to talk to themselves: A means of developing self-controlm. Journal of Abnormal Psychology, 1971, 77, 115-126.

MEYERS, M., y PARIS, S. «Children's metacognitive knowledge about reading». Journal of Educational Psychology, 1978, 70, 680-690.

MILLER, P., y BIGI, L. Children's understanding of attention, or you know I can't bear you when the waiter's running. Texto inédito. University Michigan, 1976.

Miller, G.; Galanter, E., y PribaM, K. Plaus and structure of bebavior. Nueva York: Holt, 1960.

MISCHEL, W. «Processes in delay of gratification, en L. Berkowitz (Ed.): Advances in experimental sorial psycbology (Vol. 7). Nueva York: Academic Press, 1974.

Mischel, W. «The self as the person: A cognitive sorial learning new», en $A$. Wandersman (Ed.): Bebavioristic and bumanistic approaches to personality change. Nueva York: Pergamon Press, 1975.

MISCHEL, W. «Objective and subjective rules for delay of gratification, en W. Lens (Ed.): Cognitions in buman motivation and learning. Hillsdale, N. J.: Erlbaum, 1981.

MisCHeL, W. «Metacognition and rules of delay», en J. FLavell y L. Ross (Eds.): Cognitive sorial development: Frontiers and possible futures. Nueva York: Cambridge University Press. 1981a.

MischeL, N. «A cognitive-social learning approach to assessment, en T. Merluzzi, C. Glass y M. Genest, (Ed.): Cognitive Assessment. Nueva York: Quilford Press, $1981 \mathrm{~b}$.

MisCHEL, W.; MisCHEL, H., y HoOD, S. «The development of knowledge of effective ideation to delay gratification». Texto inédito. Stanford University, 1978.

Monahan, J., y O'Leary, D. «Effects of self-instruction on rule breaking behavior». Psychological Reports, 1971, 79, 1059-1066.

MurRay, H. Explorations in personality. Nueva York: Oxford Press, 1938.

NELSON, N., y BIRKMER, J. «Role of self-instruction and self-reinforcement in the modification of impulsivity». Journal of Consulting and Clinical Psychology, 1978, 46, 183.

NISBETT, R. E., y WiLSON, T. D. «Telling more than we can know: Verbal reports on mental processes». Psychological Review, 1977, 84, 231-259.

PALKES, H.; STEWARD, M., y FREDMAN, J. «Improvement in maze performance on hyperactive boys as a function of verbal training procedures». Journal of Special Education, 1972, 5, 337-342. 
Palkes, H.; Steward, M., y KaHANa, B. «Porteus maze performance after training in self-directed verbal commands». Child Development, 1968, 39, 817-826.

Patterson, C., y Mischel, W. «Effects of temptation-inhibiting and task facilitating plans on self-control». Journal of Personality and Sorial Psychology, 1976, 33, 209-217.

RACHMAN, S., y EYSENCK, H. J. «Replay to a «critique and reformulation» of behavior therapy». Psychological Bulletin, 1966, 65, 165-169.

RAZRAN, G. "The observable unconscious and the inferable conscious in Soviet psychophysiology». Psychological Review, 1961, 68, 81-147.

ReHM, L. P. "A Self-Control Model of Depression». Behavior Therapy, 1977, 8, 787-804.

REHM, L. P. Bebavior therapy for depression: Presents status and future directions. Nueva York: Academic Press, 1981.

RIDBERG, E. H.; PARKE, R. D., y HeTHERINGTON, E. M. «Modification of impulsive and reflective cognitive style through observation of film-mediated models». Development Psychology, 1971, 5, 369-377.

ROBERTSON, D., y KEELEY, S. Evaluation of a mediational training program for impulsive children by a multiple case study design. Trabajo presentado en la American Psychological Association, 1974.

ROGERG-WARREN, A., y BAER, D. «Correspondence between saying and doing: Teaching children to share and praise». Journal of Applied Bebavior Analysis, 1976, 9, 335-354.

ROKEACH, M. Beliefs, attitudes and values. San Francisco: Jossey-Bas, 1968.

RYAN, E. B. «Identifying and remediating failures in reading comprehension: Toward an instructional approach for poor comprehenders, en T. G. Waller y G.E. Mac Kinnon (Eds.): Advances in reading research (vol. 2): Nueva York: Academic Press, 1981.

SCHLESER, R.; MEYERS, A., y COHEN, R. «Cross task consistency as a function of cognitive level and instructional package». Texto inédito. Memphis State University, 1978.

SCHNEIDER, M., y Robin, A. «The turtle technique: A method for the self-control of impulsive behavior». Texto inédito. State University of New York at Stony Brook, 1975.

SCHWARTZ, R. M., y GotTMAN, J. M. "Toward a task analysis of assertive behavior». Journal of Consulting and Clinical Psychology, 1976, 44, 910-920.

SHERVIN, H., y DiCKMAN, S. «The psychology unconscious: A necessary assumption for all psychological theory?». American Psychologist, 1980, 35 (5), 421-434.

SINCLAIR-DE-ZWART, $H$. «A possible theory of language acquisition within the general framework of Piaget's developmental theory, en D. Elkind y J. Flavell (Eds.): Studies in cognitive development. Londres: Oxford University Press, 1969.

Smith, E. R., y Miller, F. O. «Limits on perception of cognitive processes: A reply to Nisbett and Wilson». Psychological Review, 1978, 85, 355-362.

SPIVACK, G., y SHURE, M. Social adjustment of young children: A cognitive approach to solving real-life problems. San Francisco: Jossey-Bass, 1974.

STONE, G.; HINDS, W., y SCHMIDT, G. «Teaching mental health behavior to elementary school children». Professional Psychology, 1975, 6, 34-40.

VYGOTSKY, L. Thought and language. Nueva York, Wiley, 1962.

WIEST, W. M. «Some recent criticism of behaviorism and the learning theory». Psychological Bulletin, $1967,67, \mathrm{n} .97$.

WOLPE, J. Psychotherapy by reciprocal inbibition. Standford: Standford University Press, 1958.

WOLPE, J. The practice of behavior therapy. Nueva York: Pergamon Press, 1973. 